Scarpa, G. F. \& L. M. Anconatani. 2021. La "Materia Médica Misionera" atribuida al jesuita Pedro de Montenegro en 1710 (II): Identificación de las plantas y sus usos contra trastornos del aparato reproductor. Bonplandia 30(1): 67-89.

\title{
La “Materia Médica Misionera" atribuida al Jesuita Pedro de Montenegro en 1710 (II): IdENTIFICACIÓN de LAS PLANTAS Y SUS USOS CONTRA TRASTORNOS DEL APARATO REPRODUCTOR
}

\author{
The "Materia Médica Misionera" attributed to the Jesuit Pedro Montenegro in 1710 part II: \\ Identification of plants and their uses against disorders of the reproductive system
}

\section{Gustavo F. Scarpa ${ }^{1} \mathbb{D}$ \& Leonardo M. Anconatani²]}

\begin{abstract}
Resumen: Se identifican las plantas empleadas para el tratamiento de los trastornos del aparato reproductor mencionadas en la "Materia Médica Misionera" (M.M.M.) atribuida al jesuita Pedro de Montenegro fechada en 1710. Se describen sus indicaciones terapéuticas en su contexto médico histórico de referencia y se discuten las relaciones de estos resultados con la etnobotánica médica folk actual de la zona de las "misiones". Las identidades de las plantas se estimaron sobre la base de las descripciones textuales y representaciones gráficas extraídas de la fuente de datos, así como de las correspondencias botánicas de los nombres vulgares obtenidas a partir de una búsqueda exhaustiva de las mismas en 59 obras. Un total de 57 taxa empleados contra trastornos del aparato reproductor pudo ser identificado botánicamente, los cuales refieren a 102 datos etnobotánicos propiamente dichos. Aunque se evidencian pocas plantas $(42,1 \%)$ y usos medicinales $(5,8 \%)$ que son también compartidos entre la M.M.M. y los referidos en obras actuales, esto indicaría cierto grado de continuidad respecto a la farmacopea utilizada y a criterios etiológico-terapéuticos propios de la etnobotánica médica criolla del Paraguay.
\end{abstract}

Palabras clave: Aparato reproductor, etnobotánica misionera, plantas medicinales.

Summary: Plants are here identified that are mentioned in the "Materia Médica Misionera" (M.M.M.), attributed to the Jesuit Pedro Montenegro in 1710, to be used against disorders of the reproductive system. Their therapeutic properties are described in their medical historical context of reference, and the relationships of these results with present folk medical ethnobotany of the "misiones" region are discussed. Plant identities were inferred based on written descriptions and graphic representations extracted from the data source, as well as the botanical correspondences of the vernacular names obtained from an exhaustive search in a total of 59 publications. A total of 57 taxa (from 102 ethnobotanical data) used against reproductive system disorders could be identified. Even though few plants $(42,1 \%)$ and medicinal uses $(5,8 \%)$ are shared between the M.M.M. and those of current works, this observation would indicate a certain degree of continuity with respect to the pharmacopoeia used and the etiological-therapeutic criteria characteristic of the folk medical ethnobotany of Paraguay.

Key words: Medicinal plants, missionary ethnobotany, reproductive system.

\footnotetext{
${ }^{1}$ División Botánica del Museo Argentino de Ciencias Naturales "Bernardino Rivadavia" (MACN-CONICET). E-mail: gscarpa@macn.gov.ar

${ }^{2}$ Universidad de Buenos Aires, Facultad de Farmacia y Bioquímica, Departamento de Farmacología, Cátedra de Farmacobotánica y Museo de Farmacobotánica "Juan A. Domínguez".
} 


\section{Introducción}

La "Materia Médica Misionera" (M.M.M.), herbolario fechado en 1710 atribuido al jesuita Pedro de Montenegro ([1710] 1945), es considerado por muchos historiadores como uno de los principales tratados de botánica médica de todo el período colonial en América (Deckmann Flecket et Poletto, 2012; Poletto, 2014). Debido a la ausencia de estudios de carácter etnobotánico sobre esta obra, los autores nos propusimos como objetivo general efectuar una caracterización integral de la misma desde esta perspectiva. Como primer contribución al respecto (Scarpa et Anconatani, 2019) hemos efectuado una sistematización, cuantificación e interpretación de la totalidad de aplicaciones medicinales y de otro tipo asignadas a cada una de las entidades vegetales mencionadas en dicha obra. Los resultados de este estudio redundaron en la identificación de 1234 usos totales acerca de 141 entidades vegetales referidas en la M.M.M. por su nombre vernáculo. Los usos medicinales -que representaron el $92,3 \%$ del total (1142 datos)- estaban referidos principalmente al tratamiento de trastornos del aparato digestivo (300; 26,2\%), seguidos de los empleados como "vulnerarios" $(143 ; 12,5 \%)$ y los indicados para el "aparato reproductor" (101; 8,8\%) (Scarpa et Anconatani, 2019).

La gran cantidad de datos identificados, la complejidad que implica la identificación taxonómica de las plantas y la dificultad en la interpretación de las indicaciones terapéuticas que sobre ellas se refieren, nos ha obligado a particularizar el análisis etnobotánico propiamente dicho por separado para cada una de las subcategorías médicas (o sistemas corporales) a las que se hace referencia. Dentro de estas últimas, merece especial importancia la referida al aparato reproductor no solo por la cantidad y diversidad de datos etnobotánicos involucrados, sino por incluir numerosas indicaciones terapéuticas no comúnmente mencionadas (o muy escasamente) en la medicina popular argentina contemporánea. Ejemplo de ello, son las consignadas como anafrodisíacos, afrodisíacos, contra la espermatorrea, la "hipocondría menárquica", esterilizantes, "vivificantes" y para el tratamiento del rejuvenecimiento vaginal. Es por ello que en esta contribución el análisis se limita solo a aquellas entidades vegetales cuyas indicaciones terapéuticas se refieren al tratamiento de los trastornos vinculados al aparato reproductor, así como la interpretación de dichas aplicaciones en el contexto histórico médico en el que tuvieron lugar.

A pesar del destacado valor histórico que la M.M.M. posee para la etnobotánica médica y para la farmacobotánica actual, contamos con escasos trabajos que analizan las identidades botánicas de solo algunas de las plantas allí referidas. El antecedente más importante al respecto lo constituye una addenda que Domingo Parodi (1886) adjuntara a sus "notas sobre las plantas usuales del Paraguay, Corrientes y Misiones" publicadas por él mismo (Parodi, 1877). En aquel artículo D. Parodi transcribe una carta que su amigo Martín Spuch le enviara anoticiándole sobre un manuscrito del jesuita Pedro de Montenegro fechado en 1711 que hallara en la biblioteca del conde de Osuna (España), acompañado de una larga lista de nombres vulgares en idioma tupí-guaraní y en español de las plantas citadas en dicha obra. A continuación de tal epístola, D. Parodi (1886) correlaciona dichos nombres vernáculos con identificaciones botánicas de su cuño, sobre la base de su conocimiento de los fitónimos en guaraní correspondientes a las plantas que él mismo estudió y recopiló en Paraguay, Corrientes y Misiones. Sin embargo, consideramos que estas identificaciones serían de escaso valor debido a que no solo abarcan a una pequeña parte de las más de doscientas entidades botánicas consideradas en la M.M.M., sino que muchas son claramente incompletas o efectuadas solo a nivel de familia botánica y que además fueron realizadas teniendo en cuenta solamente las correspondencias botánicas con la nomenclatura vernácula. Otro antecedente menor al respecto son los trabajos de Ricciardi et al. (1996) y Ricciardi et Chifa (2014), en donde se ensayan algunas identificaciones botánicas propias sin citar método, criterio, ni bibliografía respaldatoria de tales correspondencias, varias de las cuales son parciales, dudosas o confusas. La aplicación de los criterios antedichos no permite contar con la precisión que pudiera 
haberle brindado su contrastación con: 1) la información que aporta para su identificación botánica cada una de las láminas que ilustran las plantas en el manuscrito de Buenos Aires; 2) las descripciones botánicas que sobre las mismas efectúa a lo largo del texto en cuanto a su morfología, hábitat, forma de vida, fenología y aspectos varios de las partes utilizadas; y 3) las propiedades farmacológicas asociadas a cada una de ellas. Por último, en el trabajo de Stampella et al. (2019) se identifican botánicamente las entidades vegetales correspondientes a 12 láminas de la M.M.M., las que fueron elegidas según la condición "comestible" de sus frutos (frutales).

En cuanto a los antecedentes sobre estudios históricos referidos a la "etnobotánica médica misionera" en Argentina, además de los trabajos de Anconatani et Scarpa (2015) y de Scarpa et Anconatani (2017) sobre la Misión franciscana de Laishí entre los Qom del Chaco formoseño -donde se acuña por vez primera dicha expresión-, podemos citar los de Rosso (2011) y Rosso et Scarpa (2012) respecto al jesuita Florián Paucke entre los moqoit del Chaco santafecino, además del ya citado de Scarpa et Anconatani (2019) sobre la M.M.M.

Al comentar los herbolarios escritos a comienzos del siglo XVIII por misioneros religiosos que ejercieron su labor religiosa en Norteamérica, Kay (1976) y Foster (1979) coinciden en observar una evidente concordancia entre las indicaciones terapéuticas -y sistema médico- allí registradas con las actualmente empleadas en la medicina mestiza (o criolla) de México. Para nuestro país, una hipótesis semejante fue planteada por Scarpa $(2000,2012)$ al estudiar la medicina de los criollos del oeste de Formosa, la cual respondía a los mismos criterios etnomédicos que la etnobotánica médica misionera de esta parte del mundo, particularmente, los explicitados en la introducción a la M.M.M. que aquí tratamos. Esta hipótesis permite avizorar el significativo valor que tendría un estudio exhaustivo de este tipo como para poner a prueba dicho planteo.

El objetivo de esta contribución consiste en identificar desde el punto de vista botánico las plantas empleadas para el tratamiento de los trastornos del aparato reproductor, describir sus indicaciones terapéuticas en su preciso contexto médico histórico de referencia y discutir las relaciones de estos resultados con la etnobotánica médica folk actual de la zona de las misiones.

\section{Materiales y Métodos}

El marco teórico-metodológico empleado corresponde a la etnobotánica histórica, el cual considera a los datos del pasado como una fuente de información primaria sobre los cuales se aplica el método clásico etnobotánico (ver Medeiros, 2009; Rosso, 2011; Rosso et Scarpa, 2012). La fuente primaria sobre la que se trabaja corresponde a la primera edición del manuscrito fechado en el año 1710 titulado "Materia Médica Misionera" publicada por la Biblioteca Nacional de Argentina en el año 1945, cuya autoría se asigna por el editor al misionero jesuita Pedro de Montenegro ([1710] 1945). Tal como se indicara en nuestra primera aproximación al estudio etnobotánico de la M.M.M. (Scarpa et Anconatani, 2019), la estrategia metodológica aplicada para cumplimentar los objetivos propuestos en esta contribución involucra una serie de pasos que incluyen: a) ordenamiento de toda la información sobre usos medicinales de las plantas en una base de datos que responde al programa MS-Access 2007 -la cual se clasifica en subcategorías etic (aparato reproductor, digestivo, respiratorio, etc.) tal como se procede usualmente según la metodología etnobotánica-; b) interpretación ordenada hasta donde nos resultara posible- de cada una de las indicaciones terapéuticas a las que aluden los usos medicinales identificados a lo largo de la obra, a partir del empleo de bibliografía acerca de la medicina y de la botánica médica de la época tales como las obras históricas de Pisonis (1658); Vidal (1782); Venegas (1788); Bertoni([1927] 2008) y Montesano Delchi (1913), entre otras, y c) un análisis cuantitativo de los resultados.

A los fines de maximizar la precisión en la estimación de la identidad botánica de las plantas referidas en el tratamiento de afecciones del aparato reproductor, la metodología particular empleada involucró el análisis comparado de informaciones de 
distinto origen provenientes de la fuente considerada, entre las que se incluyen: a) las correspondencias botánicas encontradas en la bibliografía para cada uno de los nombres vulgares citados en la M.M.M. -en idioma español, guaraní y tupí- con la nomenclatura científica actual, las cuales fueron ordenadas y sistematizadas en una base de datos que responde al programa MS-Access 2007; b) la rica descripción morfológica, autoecológica, corológica, fisonómica, utilitaria y del aspecto general de las plantas referidas en el texto de la M.M.M., c) las representaciones gráficas de las mismas en los dibujos reproducidos en las láminas (ej. Fig. 1); y d) la interpretación de los niveles de congruencia y articulación entre estas fuentes de datos.

El método seguido como primer paso para identificar botánicamente las entidades vegetales referidas en la M.M.M. a partir de

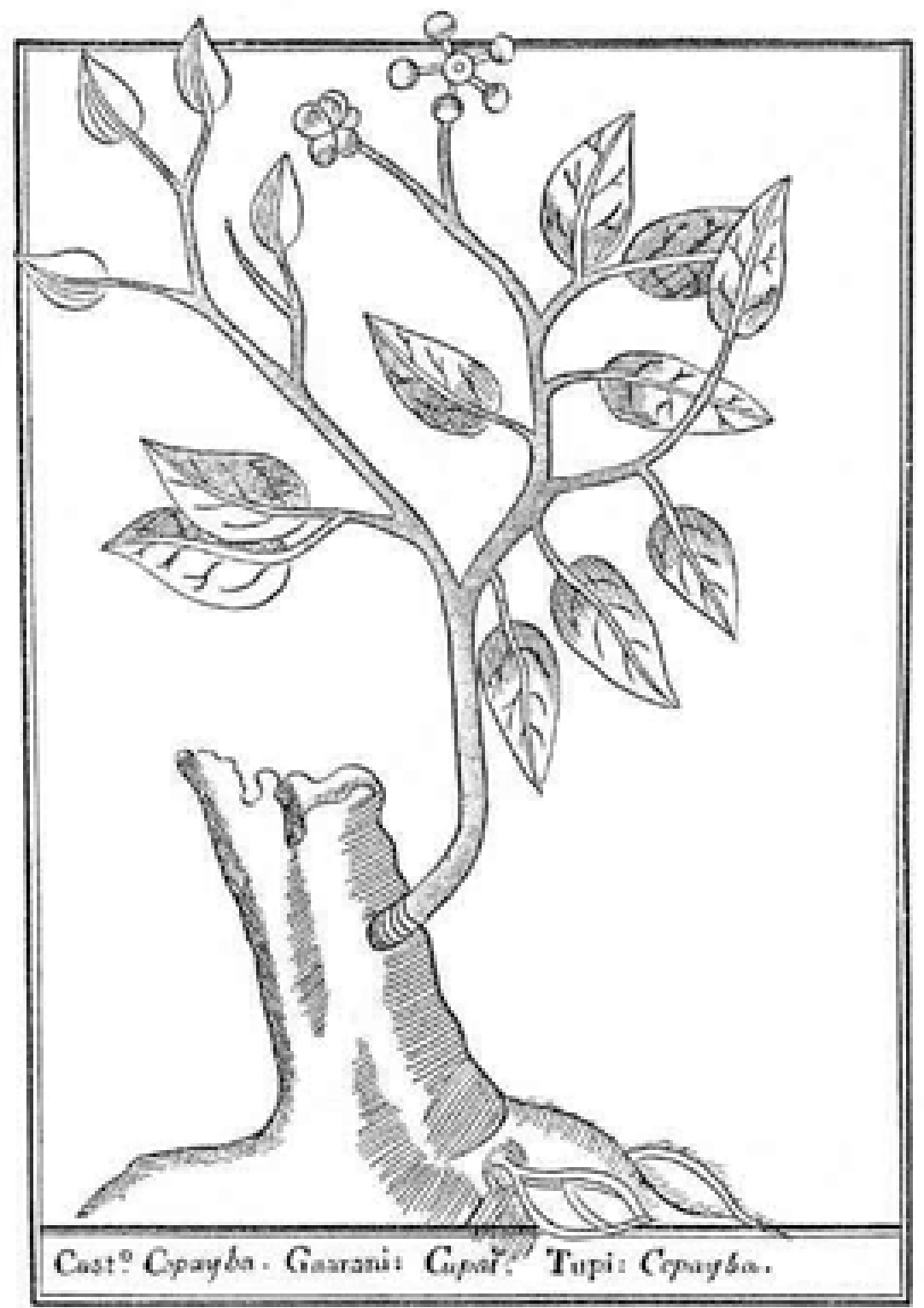

Fig. 1. Lámina $\mathrm{n}^{\circ} 77$ (Copaifera langsdorfii).

Fig. 1. Drawing n ${ }^{\circ} 77$ (Copaifera langsdorfii). 
los nombres vulgares es el utilizado por Rosso et Scarpa (2012); Campos Navarro et Scarpa (2013) y Scarpa et Rosso (2018, 2019). Este consiste en compilar de manera exhaustiva todas las correspondencias botánicas referidas para un fitónimo determinado publicadas para el mismo complejo biocultural de referencia. Este método procura reproducir la primera fase de toda investigación etnobotánica consistente en identificar en primer término las correspondencias botánicas de los nombres vulgares referidos por los informantes a partir de colecciones de ejemplares de herbario, con el fin de asociar la información que estos refieren. Para ello, se efectuó una exhaustiva búsqueda bibliográfica que involucró la consulta de 59 (cincuenta y nueve) obras que señalan las correspondencias botánicas de nombres vulgares empleados en el sur del Cono Sur americano. En todo momento las identificaciones estimadas fueron las que maximizaron el ajuste entre todas estas fuentes de información a los fines de lograr la mayor precisión de las mismas. En los casos en que varias identificaciones podían ser posibles -como efectivamente ocurre-, nos inclinamos hacia las que concentraban el mayor número de coincidencias entre tales fuente de datos, incluido el número de citas bibliográficas que referían tales correspondencias entre nombre vulgar y nombre científico. En los casos en que por aplicación de este método no se pudo hallar una identificación precisa, dejamos indicada la misma hasta el nivel de género botánico o bien no se consideró posible efectuarla (si la misma podía corresponder a más de dos géneros).

El tratamiento sistemático empleado fue el que sigue la Flora Argentina (2019) y la Flora del Cono Sur (2019), bases de datos online publicadas por el Instituto de Botánica Darwinion.

\section{Resultados}

\section{Identificación botánica de las plantas referidas}

En la M.M.M. muchas de las plantas americanas son descriptas en función de su comparación con plantas europeas (i.e. "pan de puerco"; "aristoloquía rotunda", etc.) o mexicanas (i.e. "xalapa") que los jesuitas consideraban como los prototipos de las mismas según su bagaje previo de conocimientos. Este se hallaba explícitamente influenciado por obras clásicas de autores todavía en boga en el siglo XVII tales como Pisonis, Jacobo Bonti, Dioscórides, Laguna y Mathiolo. Sin embargo, este abrevar en obras de botánicos prelinneanos redundó en la utilización de fitónimos procedentes de una multitud de pueblos -tanto de América como del Viejo Mundo-, ya que los nombres vulgares en dicha época eran los que constituían la "nomenclatura" de los naturalistas. Esta última mixturaba tanto nombres guaraníes y españoles, como portugueses y tupíes, idiomas tanto de la zona geográfica donde se ubicaban las reducciones donde actuaron los jesuitas, como provenientes de otros territorios referidos en las obras de los autores pre-linneanos. Un ejemplo de ello se puede observar en la obra de Pisonis -sobre la que se basan varias de las descripciones botánicas citadas en la M.M.M.-, la cual se refiere según Domínguez (1928: 27) a plantas y nombres propios de las "provincias de Rio Grande del Norte, Parahyba, Pernambuco, Alagoas, Sergipe, Bahía, Cearà y la isla de Marañon". De esta manera, en la M.M.M. se establecen comparaciones y correspondencias entre el aspecto de plantas -e incluso sus nombres vulgares- propias de las reducciones jesuíticas con la de otras procedentes de zonas separadas de ellas por miles de kilómetros de distancia. Este procedimiento habría aportado, indudablemente, numerosas confusiones para una identificación botánica precisa de las plantas, ya que las mismas corresponderían a provincias y distritos fitogeográficos diferentes a los recorridos por los misioneros.

Debido a la complejidad que tal situación amerita, a la minuciosidad propia que conlleva el método aplicado y a los fines de estimar la identidad botánica de cada una de las entidades vegetales referidas en la M.M.M. con aplicaciones sobre el aparato reproductor, se analizan los argumentos que sustentan las identificaciones estimadas para cada una de ellas a continuación por separado.

"Anguaí", "árbol del Menjui", "copal calaminta", “ibira-payé" (lámina 2): Se 
reconocen en la M.M.M. cuatro etnoespecies: Dos blancas (una femenina y otra masculina) y dos negras (una "mirí" y otra "guazú"). Bajo el nombre vulgar "anguaí" o "aguaí" se suelen citar para el área referida en el texto ("bosques de las misiones") a especies de los géneros Chrysophyllum (C. gonocarpum (Mart. \& Eichler ex Miq.) Engl. y C. marginatum (Hook. \& Arn.) Radlk.) y Myroxylon. Sin embargo, respecto a las especies del primer género no coinciden ni las propiedades ni la descripción general de estos árboles con las entidades descriptas en la M.M.M. En efecto, no resultan congruentes las propiedades mencionadas en la M.M.M. tanto respecto a su condición de exudar un "bálsamo" oloroso, su fuste recto (propicia "para tirantes") como así tampoco la morfología de sus hojas (compuestas, lisas -"suaves"- y de márgenes ondulados -"medio cerradas al sol"-). Sin embargo, estas características y los fitónimos "árbol del Menjui" (o Benjuí) y "anguaí" concuerdan perfectamente con el taxón Myrocarpus frondosus Allemão según Bertoni [1927] (2008), Cadogan (1972), Bernardi (1984), Gatti (1985), López et al. (1987), González Torres (2003); De la Peña et Pensiero (2004). Esta especie se halla tanto en los bosques tropicales lluviosos de Argentina (Corrientes y Misiones), Paraguay y Brasil (estados de Paraná, Santa Catarina y Rio Grande do Sul) según la Flora del Cono Sur (2019), distribución coincidente con "la zona de las misiones" referidas en la M.M.M.

"Ibirá ysy", “árbol del gumi elemi”, “isica del Uruguay y Brasil", "isica del Paraguay", "isica ribá" (lámina 3): Consideramos que, de los dos taxas de "isicas" mencionados como traídos desde el Paraguay, el referido como "negra" sería Protium heptaphyllum (Aubl.) Marchand, ya que es la que hasta hoy es comercializada y utilizada por excelencia como "ysy" o "ysyca" en ese país (Arenas, 2007). La referida como "blanca" sería, según este autor, otra especie de Protium sp. que no pudimos reconocer. Coinciden con estas identificaciones las citas de Martius (1843), Montesano Delchi (1913), Pío Correa (1926), Bertoni ([1927] 2008), Bertoni ([1940] 2010), Cadogan (1972), Gatti (1985); López et al. (1987).
“Guayacán” (lámina 7). Aunque bajo esta lámina se describen cuatro etnoespecies, solo se dibujan dos (estampa $1^{\circ}$ y estampa $2^{\circ}$ ). El que Montenegro (1945) refiere como $2^{\circ}$ estampa y que denomina como "Ibirá ehé" o "Guayacán" es el que considera como medicinal. Esta estampa corresponde con bastante precisión a Libidibia paraguariensis (D. Parodi) G. P. Lewis por sus hojas de tipo mimosoideas, fruto como "algarroba negra", madera de gran dureza y por su típica parte utilizada en terapéutica (su corteza). Coinciden con esta correspondencia Hassler (1909), Gatti (1985), González Torres (2003), De la Peña et Pensiero (2004); Scarpa (2012).

"Arazá", "guayabas", "hezaé tibaé”, "guayaba campesina" (láminas 11 y 12): Menciona tanto "guayabas" silvestres como cultivadas. Respecto a esta última podemos inferir sin temor a equivocarnos que se trataría de Psidium guajaba L. Respecto a las guayabas silvestres coincidimos con las identificaciones citadas en Stampella et al. (2019), a saber: Psidium australe Cambess., $P$. australe Cambess. var. argenteum (O. Berg) Landrum, $P$. guineense Sw., $P$. kennedyanum Morong, $P$. misionum D. Legrand, $P$. salutare (Kunth) O. Berg var. mucronatum (Cambess.) Landrum, P. salutare (Kunth) O. Berg var. sericeum (Cambess.) Landrum.

"Granadilla de la pasión", "granadilla de la pasión amarilla", "mburucuyá amarillo silvestre" (láminas 14, 15 y 16): La planta ilustrada en lámina 15 , a juzgar por la descripción de su fruto, de sus flores y de su frecuencia de cultivo, sería indudablemente Passiflora edulis Sims. Las demás especies referidas corresponden a varias especies del género Passiflora L., según Stampella et al. (2019) a P. alata Curtis, $P$. amethystina J. C. Mikan, P. caerulea L., P. cincinnata Mast., P. elegans Mast., P. morifolia Mast., $P$. suberosa L. y P. umbilicata (Griseb.) Harms. Sin embargo, a juzgar por las numerosas citas bibliográficas halladas, el "mburucuyá" más común en los territorios de las misiones transitados por Montenegro sería $P$. caerulea (Rolón, 1910; Bertoni, [1927] 2008; Bertoni, [1940] 2010; Storni, 1944; Cadogan, 1955; Schulz, 1963; Martínez Crovetto, 1968; Arrillaga de Maffei, 1977; Soraru et Bandoni, 
1978; Martínez Crovetto, 1981; Gatti, 1985; González Torres, 2003; Pirondo, 2016).

"Purga criolla", "corregüela" (lámina 18): Sobre la base del color (morado), morfología (campanulada) floral y foliar ilustrada, de su hábito malezoide y de las correspondencias citadas por Bertoni ([1927] 2008) y Gatti (1985), nos inclinamos a considerar que se trata de una especie del género Ipomoea.

"Acetosa (o acedera) mayor", "oxilapato", "romaza" (lámina 20): Por la morfología de las hojas y flores, presencia de tubérculos dibujados en la ilustración, así como por la descripción del texto, correspondencias botánicas halladas en la bibliografía (Montesano Delchi, 1913 y González Torres, 2003) y el uso alimenticio de sus órganos subterráneos, se trataría sin dudas de una especie del género Oxalis, aunque no se puede determinar su especie.

"Llantén silvestre peludo", “caáyuquí” (lámina 26): Tanto por su hábito (hierba brevicaule), morfología foliar y de la inflorescencia que se ilustran en la lámina, como por la descripción general del texto, las correspondencias y usos medicinales citados en la bibliografía (Hassler, 1909; Bertoni, [1927] 2008; Gatti, 1985; De la Peña et Pensiero, 2004), corresponde indudablemente a Plantago tomentosa Lam.

"Esquinanto menor" (lámina 28): Tanto por la ilustración de la planta, como por la descripción del texto y correspondencias bibliográficas (Martius, 1843; Hieronymus, [1882] 1930; Hassler, 1909; Rolón, 1910; Pío Correa, 1926; Bertoni, [1927] 2008; Bertoni, [1940] 2010; Storni, 1944; Cadogan, 1955; Moreno Azorero, 1985; Gatti, 1985; González Torres, 2003; De la Peña et Pensiero, 2004; Martínez Crovetto, 2012; Scarpa et al., 2016), se trataría de Cyperus sesquiflorus (Torr.) Mattf. \& Kük.

"Aguapé”, "aguapé guazú" (lámina 30): "Dos especies de agupé tan parecidas en la flor que apenas se distinguen la una de la otra; pero sí lo son en las ojas, porque la una son casi redondas, y de un jeme de ancho, y las otras son puntiagudas y casi al pie angostas [sería Pontederia rotundifolia L. f.]: las anchas tienen unas como vejigas del tamaño de un huevo pequeño cerca de la raiz" [por lo cual la primera especie sería Pontederia crassipes Mart]. Las demás especies de Pontederia presentes en la zona no son flotantes, lo cual las descarta. En función de este párrafo, de la fisonimia de la planta según la lámina y de sus correspondencias con su nombre vulgar, los taxa referidos se tratarían de Pontederia crassipes (Fiebrig-Gertz, 1923; Bertoni, [1940] (2010); Cadogan, 1955; Arrillaga de Maffei, 1969; Cadogan, 1972; Ratera et Ratera, 1980; Toursarkissian, 1980; Martínez Crovetto, 1981; Moreno Azorero, 1985; González Torres, 2003; De la Peña et Pensiero, 2004 y Martínez Crovetto, 2012) y Pontederia rotundifolia (Arrillaga de Maffei, 1969; Gatti, 1985; De la Peña et Pensiero, 2004).

"Mastuerzo indico" (lámina 36): Según la descripción de su hábito, morfología de su parte aérea, sabor de su parte aérea, aspecto de sus flores y frutos, características de la ilustración y correspondencias de su nombre vulgar en las citas bibliográficas (Schulz, 1963; Sorarú et Bandoni, 1978; Martínez Crovetto, 1981; González Torres, 2003), consideramos que se trata de Lepidium didymum L., planta medicinal de uso común en las tierras de las misiones.

"Contrayerba" "taropé, "contra yerba femenina" (láminas 38 y 39): El aspecto de la planta según la ilustración (hábito, morfología foliar y del fruto), la descripción del texto y la mayoría de las correspondencias botánicas citadas en la bibliografía permiten concluir que se trataría de Dorstenia brasiliensis Lam., ya que los demás taxa referidos con dicho nombre vulgar difieren significativamente de las ilustraciones y de la descripción del texto (Rolón, 1910; Montesano Delchi, 1913; Bertoni, [1927] 2008; Bertoni, [1940] 2010; Storni, 1944; Cadogan, 1955; Gatti, 1985; Arenas, 1997; González Torres, 2003; De la Peña et Pensiero, 2004).

"Canchalagua", "Capiî irópitá" (lámina 40): Según el aspecto general de la planta ilustrada, sus flores amarillas, su distribución en Tucumán y Chile (tal como refiere la descripción) (Flora del Cono Sur, 2019) y por las correspondencias botánicas citadas de su nombre vulgar (Gatti, 1985; Correa, 2003; De la Peña et Pensiero, 2004), corrrespondería a Schkuhria pinnata (Lam.) Kuntze ex Thell. Asimismo, sus propiedades medicinales, por otro parte se hallan muy difundidas en el norte argentino. 
"Añangapirū-cáa", "yerba de la murta" (lámina 41): Tanto el aspecto de la planta dibujado en la ilustración como la descripción del texto coinciden en que se trataría de una especie del género Tagetes, debido al aspecto general de la planta, de sus flores (amarillas y con involucro alargado), frutos y por su característico aroma, debido a la presencia de glándulas oleíferas en sus hojas. Asimismo, sus usos medicinales -incluso el referido como vermífugo- resultan muy difundidos hasta hoy en el Nordeste y Noroeste argentino donde varias especies de dicho género se conocen con los nombres de "chinchilla" y "suico", respectivamente (De la Peña et Pensiero, 2004). No se debe confundir esta etnoespecie con el "Añangapirí mirí" ni con el "Añangapirí guazú" mencionadas en lámina 10, sobre las cuales se consignan descripciones y usos medicinales distintas a las aquí indicadas.

"Mboycaá" (lámina 44): De acuerdo con las descripciones señaladas en el texto respecto al color blanquecino de sus flores y al látex que exuda la planta al ser cortada, como así también por las características generales de la planta dibujadas en la ilustración y las correspondencias de su nombre vulgar citados en la bibliografía (Gatti, 1985; González Torres, 2003; De la Peña et Pensiero, 2004), nos permiten inferir que se trataría de Asclepias mellodora A. St.-Hil.

"Aristoloquia rotunda masculino", "aristoloquia rotunda femenina" (láminas 46 y 47): No concordamos con Ricciardi et al. (1996) respecto a que la planta referida sea una especie de Aristolochia, aunque por su nombre se corresponda con $A$. rotunda L. Esto se debe a la incongruencia de la descripción de la planta en el texto y en la ilustración, especialmente al referirse a que "La bayna cuando el fruto está en sazón se tornan coloradas, la cual es tierna como frutilla, y muy viscosa ó húmeda", ya que las especies de ese género poseen frutos secos (cápsulas septicidas). Esta incongruencia se confirma con la procedencia europea de $A$. rotunda (de allí lo de "célebre planta"), lo que resultaría contradictorio con su presencia en estas tierras ("...se hallan en estas tierras de las Misiones"). En suma, no podemos deducir a qué identidad botánica se hace referencia en este caso.
"Carachí blanco", "pan de puerco", "pan porcino", "ciclamino" (lámina 48): Desde la época de Linneo se llama "pan de puerco" en Europa a Cyclamen europaeum L. (Colmeiro, 1859; Deckman Fleck et Poletto, 2012), prototipo a partir del cual el autor de la obra describe a la planta en cuestión (también la llama "ciclamino" aludiendo a esta última especie). Alude, según la descripción del texto y las correspondencias botánicas sudamericanas con su nombre vulgar según las citas bibliográficas, a especies de Dioscorea (Pisonis, 1658; Martius, 1843; Montesano Delchi, 1913; Bertoni, [1940] 2010; Cadogan, 1955; De la Peña et Pensiero, 2004; Martínez Crovetto, 2012). De las cuatro que describe solo podemos identificar que una de ellas corresponde a Dioscorea sinuata Vell.

"Molle de Castilla", "lentisco blanco" (lámina 49): Según las características de la ilustración y las correspondencias halladas se conoce como "aguaribay" y "molle de Castilla" en el sur del Cono Sur tanto a Schinus molle L. como a S. areira L. (Sorarú et Bandoni, 1978; González Torres, 2003; De la Peña et Pensiero, 2004).

"Aguaraībaĩ miri", "aguaraíbaí" (lámina 50): El descripto como "molle negro masculino" sería Schinus terebenthifolia Raddi tanto por sus típicos internodos alados e inflorescencias axilares como por las correspondencias botánicas citadas (Rolón, 1910; Fiebrig-Gertz, 1923; Bertoni, [1927] 2008; Bertoni, [1940] 2010; Gatti, 1985). No pudimos reconocer el femenino.

"Caácambî", "xalapa”, "lechetrez" (lámina 51): Según las correspondencias botánicas de su nombre vulgar en las citas bibliográficas pudimos llegar a identificar que se trata de una especie del género Euphorbia (Martius, 1843; Rolón, 1910; Bertoni, [1940] 2010; Sorarú et Bandoni, 1978; Gatti, 1985; González Torres, 2003).

"Caané guazú" (lámina 53): Tanto la descripción del texto como la ilustración y las correspondencias citadas en la bibliografía coinciden en que se trataría del conocido "paico": Dysphania ambrosioides (L.) Mosyakin \& Clemants (Hieronymus, [1882] 1930; Rolón, 1910; Bertoni, [1927] 2008; Domínguez, 1928; Cadogan, 1955; 
Toursarkissian, 1980; Martínez Crovetto, 1981; Arenas, 1997; González Torres, 2003; De la Peña et Pensiero, 2004; Martínez Crovetto, 2012; Scarpa, 2012; Scarpa et Anconatani, 2017).

“Toro caá" (lámina 56): La mayoría de las correspondencias botánicas encontradas en la bibliografía asocian este fitónimo con varias especies del género Pterocaulon (Asteraceae) (Hassler, 1909; Bertoni, [1927] (2008); Bertoni, [1940] (2010); Gatti, 1985; González Torres, 2003; De la Peña et Pensiero, 2004; Freire et Molina, 2009). Sin embargo, consideramos aquí que por las características mencionadas en el texto acerca de sus hojas, flores, fruto ("de un vacio graciocisimo"), destacada condición forrajera, aspecto general de la planta en la ilustración y por las siguientes correspondencias citadas en la bibliografía (De la Peña et Pensiero, 2004; Scarpa et al., 2016), el taxón correspondería a Crotalaria incana L. (Fabaceae).

“Ajenjo póntico", “artemisa”, “absintio póntico", "sandía rogué miri" (lámina 57): Aunque las virtudes mencionadas en el texto corresponden a la célebre Artemisia pontica L. o "absintio póntico" o "ajenjo póntico"-cuyas propiedades medicinales son mencionadas por Dioscórides tal cual se explicita en la M.M.M.-, allí también se hace alusión con el nombre de "artemisa" a otra planta de crecimiento espontáneo como sucedáneo de esta: “...hállase cerca de las aguas en partes de tierras pingüe, y á veces cerca de los sembrados á sus orillas.”; “...y cierto, que á falta de este [ $A$. pontica] me he valido de aquella varias veces con buen uso". Tanto por el hábito malezoide señalado en el texto, como por el aspecto general de la planta -del texto e ilustración-, de sus flores, el sabor amargo de su parte aérea y por la correspondencia botánica de "sandía rogué mirí" encontrada (Hermida et Galli, 2019), consideramos que se trataría de Parthenium hysterophorus L. Actualmente en todo el Chaco argentino se emplea esta planta por sus propiedades medicinales con el nombre de "altamisa" o "artemisa" ("del bordo", "del campo" o "cimarrona") (Scarpa, 2012; Hermida et Galli, 2019) en una clara refonologización del prototipo europeo arriba señalado.
"Caarurú morotí" (lámina 59): En la descripción del texto se distingue entre plantas "macho" y "hembra". Las características de la descripta como "hembra" (la más importante desde el punto de vista medicinal) coinciden ajustadamente con Amaranthus viridis L., tanto por la descripción de la planta en el texto, como por la morfología y máculas de sus hojas, tipo y disposición terminal de sus inflorescencias, por su hábito y por el uso comestible en ensaladas (Scarpa, 2012). Acorde con ello son las correspondencias botánicas de su nombre vulgar citadas en la bibliografía (Hassler, 1909; Fiebrig-Gertz, 1923; Gatti, 1985; González Torres, 2003; De la Peña et Pensiero, 2004; Martínez Crovetto, 2012). Respecto a la variedad "macho" solo podemos estimar que se trataría de otra especie del mismo género, tal como indican las citas halladas respecto a las correspondencias botánicas de su nombre vulgar (Martius, 1843; Rolón, 1910; Bertoni, [1940] 2010; Storni, 1944; De la Peña et Pensiero, 2004; Scarpa et al., 2016; Scarpa et Anconatani, 2017).

"Sangre de Drago", "caáberá" (lámina 68): No cabe duda que la planta aludida se trata de Croton urucurana Baill., tanto por la descripción del texto, como por el aspecto de la planta en la ilustración y por las numerosas correspondencias unívocas citadas en la bibliografía (Hassler, 1909; Rolón, 1910; Gatti, 1985; Sainz Ollero et al., 1989; González Torres, 2003; De la Peña et Pensiero, 2004; Scarpa et al., 2016; Scarpa et Anconatani, 2017).

"Guember̂" (lámina 69): Sin dudas la planta corresponde a Philodendron bipinnatifidum Schott ex Endl., debido a que concuerdan con ella tanto la descripción del texto, el aspecto de la ilustración como así también las correspondencias citadas en la bibliografía (Martius, 1843; Bertoni, [1927] 2008; Crisci et Gancedo, 1971; Schulz, 1976; Ratera et Ratera, 1980; Toursarkissian, 1980; Arenas, 1997; De la Peña et Pensiero, 2004; Martínez Crovetto, 2012; Stampella et al., 2019).

"Lapacho", "palo santo guaycurú", "palo santo aromático", "palo santo resinoso" ( $\sin$ lámina): En la lámina 74 se alude tanto a los lapachos del Chaco de flores rosadas y hojas digitadas correspondientes a especies del género 
Handroanthus como al "palo santo" resinoso y aromático cuya descripción del texto alude al conocido Gonopterodendron sarmientoi (Lorentz ex Griseb.) A. C. Godoy-Bürki. Sin embargo, en tal lámina solo se representa al primero de ellos (Handroanthus), mientras que las indicaciones terapéuticas señaladas en el texto corresponden al segundo (G. sarmientoi). Las correspondencias botánicas con este nombre vulgar registradas en la bibliografía resultan numerosas (Montesano Delchi, 1913; Bertoni, [1927] 2008; Sainz Ollero et al., 1989; González Torres, 2003; De la Peña et Pensiero, 2004; Scarpa, 2012; Scarpa et al., 2016).

"Cupar̂" (lámina 77): Se trataría de Copaifera langsdorffii Desf. ya que coincide con el aspecto general de la ilustración, la descripción referida en el texto y la correspondencia botánica aludida a este nombre vulgar citada en la bibliografía prácticamente de carácter unívoco (Martius, 1843; Rolón, 1910; Bertoni, [1927] 2008; Bertoni, [1940] 2010; Storni, 1944; Cadogan, 1955, 1972; Ratera et Ratera, 1980; Toursarkissian, 1980; Bernardi, 1984; Gatti, 1985; López et al., 1987; Ortega Torres, 1989; González Torres, 2003; De la Peña et Pensiero, 2004; Martínez Crovetto, 2012).

“Curî̌" (lámina 79): Tanto por la descripción del texto, como por la ilustración y las numerosas citas bibliográficas que mencionan la misma correspondencia botánica, no tenemos dudas que se trata de Araucaria angustifolia (Bertol.) Kuntze (Martius, 1843; Fiebrig-Gertz, 1923; Bertoni, [1940] 2010; Ragonese et Martínez Crovetto, 1947; Martínez Crovetto, 1968; Toursarkissian, 1980; Gatti, 1985; López et al., 1987; Ortega Torres et al., 1989; González Torres, 2003; De la Peña et Pensiero, 2004; Martínez Crovetto, 2012; Scarpa et al., 2016).

"Parápará 1̂" (lámina 81): Por la descripción del texto, características de la ilustración (aspecto general del árbol y morfología del fruto -típica cápsula suborbicular-) y por las correspondencias botánicas halladas en la bibliografía para este nombre vulgar, estimamos que se trataría de especies del género Jacaranda (Rolón, 1910; FiebrigGertz, 1923; Bertoni, [1927] 2008; Bertoni, [1940] 2010; Cadogan, 1955; Schulz, 1976; Gatti, 1985; Moreno Azorero, 1985; López et al., 1987; Ortega Torres et al., 1989; Arenas,
1997; González Torres, 2003; De la Peña et Pensiero, 2004; Keller et Pirondo, 2012). En la región vegetan tres especies de este género: J. cuspidifolia Mart., J. micrantha Cham. y $J$. puberula Cham., aunque no podemos determinar fehacientemente a cuál o cuáles hace referencia en especial aquí.

"Recino arbol" (lámina 82): La descripción del texto, la ilustración de la lámina, las correspondencias botánicas de su nombre vulgar halladas en la bibliografía, conjuntamente con su condición venenosa y usos medicinales (insolación, antiinflamatorio, etc.) referidos, nos permiten inferir que se trata de Ricinus communis L. (Martius, 1843; González Torres, 2003; De la Peña et Pensiero, 2004, Scarpa, 2012; Keller et al., 2018).

"Caaroba" (lámina 84): A pesar de que como "caarobá" se conocen varias especies del género Jacaranda en la mayoría de las citas bibliográficas (Martius, 1843; Rolón, 1910; Montesano Delchi, 1913; Storni, 1944; González Torres, 2003), de ninguna manera coincide la representación del fruto en la lámina (legumbre alargada) con los que poseen las especies de este género (cápsula suborbicular). Sin embargo, sobre la base de la descripción del texto (color de sus flores), morfología foliar y fruto ilustrados en la lámina, su uso específico como antisifilítico, así como por la correspondencia indicada por Martius (1843), nos permite identificar a esta planta como Cybistax antisyphilitica (Mart.) Mart.

"Calaminta", "tamanduaí miri" (lámina 86): Aunque Ricciardi et al. (1996) sostienen que se trataría de Hedeoma multiflora Benth., la descripción de la planta en el texto y su representación en la ilustración no coinciden en absoluto con las características de dicha especie. La descripción de esta planta nativa en la M.M.M. se efectúa sobre la base del prototipo del Viejo Mundo "calaminta" (Calamintha officinalis Moench) de antigua fama medicinal en obras clásicas (Morales et Luque, 1997). Coincidimos con González Torres (2003) en que la menor de las dos entidades descriptas ("tamanduaí miri") se trataría de Glechon ciliata Benth., ya que coinciden su aspecto general, el color de sus flores, la disposición de sus hojas, la condición aromática de hojas y flores e inclusive los mismos usos medicinales (i.e. sudorífico). 
"Raíz de la China blanca", "yuápecámiri" (láminas 90 y 91): Según la descripción del texto, la ilustración de las láminas y las correspondencias botánicas de su nombre vulgar halladas en la bibliografía, podemos determinar que al menos una de las plantas correspondería a Smilax campestris Griseb. (Martius, 1843; Rolón, 1910; Bertoni, [1927] 2008; Bertoni, [1940] 2010; Cadogan, 1955; Gatti, 1985; Arenas, 1997; González Torres, 2003).

"Galanga" (sin lámina): De la descripción textual bajo "lámina 99" se puede deducir que los usos ("virtudes") son asignados a las plantas denominadas "xengibre" y "galanga" (planta sin lámina). Sobre esta última refiere que es la célebre planta que tratan Galeno, Egineta y Laguna, es decir, la especie del Viejo Mundo históricamente estudiada y referida en la bibliografía con dichos nombres vulgares: Alpinia officinarum Hance (Hurrell et al., 2008: 102). Por tanto, consideramos que se trataría de especie de origen extra-americano.

"Caápari miri" (lámina 103): Por el aspecto general de la planta y por las correspondencias botánicas halladas en la bibliografía inferimos que se trataría de una especie del género Pfaffia. Así Cadogan (1955), Gatti (1985), Arenas (1997) y González Torres (2003) refieren como tal a $P$. tuberosa (Spreng.) Hicken, mientras que De la Peña et Pensiero (2004) a $P$. glomerata (Spreng.) Pedersen. Sin embargo, en la descripción del texto se refiere explícitamente que "el caaparí mirí es batatilla de Don Antonio, que así la llaman por toda la provincia del Tucuman...", por lo que nunca podría tratarse de $P$. tuberosa debido a que no se encuentra en ninguna localidad del Noroeste de Argentina ya que vegeta en el Litoral. Por tanto, concluimos que se trata de $P$. glomerata.

"Yerba de la víbora", "macaguácaá" (lámina 109): Aunque bajo estos nombres vulgares se citan numerosas especies botánicas, acordamos con Cadogan (1955), Gatti (1985); Moreno Azorero (1985) y González Torres (2003) que se trata de Sidastrum paniculatum (L.) Fryxell, debido a que coincide perfectamente con la descripción efectuada tanto en el texto como en la ilustración hasta en los menores detalles.

"Caáberá miri", "caaberá caá" (láminas 112 y 113). El texto dice distinguir cuatro especies de díctamo, dos blancos y dos negros. Sin embargo, solo describe tres, de las cuales se pudieron identificar las últimas dos que responden al nombre común "caaberá mirí, cuyas correspondencias botánicas en la zona de las misiones se asocian a tres especies Hyptis lorentziana O. Hoffm., Cantinoa mutabilis (Rich.) Harley \& J. F. B. Pastore y Condea undulata (Schrank) Harley \& J. F. B. Pastore (Rolón, 1910; Storni, 1944; Scarpa et al., 2016; Scarpa et Anconatani, 2017). Estas especies responden bastante ajustadamente a las representadas en la ilustración de las láminas, tanto por su porte, tallo anguloso, morfología de las inflorescencias, entre otros, además de haber sido citados usos medicinales similares por Scarpa et Anconatani (2017).

"Enula campana" (lámina 114): Distingue dos entidades botánicas con este nombre vulgar. Inferimos por oposición semántica al epíteto "campestre" -señalado con referencia a la segunda en dos oportunidades (“...hállase otra campestre Henula por las campañas...")-, que la primera se trataría de Inula helenium L. (especie cultivada), ya que además se ajusta a la descripción del texto y a la ilustración de la lámina 114. La segunda, en cambio, suscita confusiones ya que indica "despues de haber escrito lo atraz referido de la segunda henula, que se halla por las campañas, hallé no ser la verdadera, y asi hallandola la hise dibujar". Asimismo, la mayoría de las citas bibliográficas hacen corresponder dicho nombre vulgar con $I$. helenium (Montesano Delchi, 1913; Saggese, 1959; De la Peña et Pensiero, 2004).

“Tabaco" (lámina 118) y “coro", “caá coro" (sin lámina): No caben dudas acerca de la identidad del tabaco en estas regiones como antiguo cultígeno. Las diversas "especies" mencionadas en el texto como "blanco" y "negro" serían indudablemente variedades hortícolas de Nicotiana tabacum L., lo cual resulta típica de cultígenos cultivados desde antaño (Martius, 1843; Montesano Delchi, 1913; Fiebrig-Gertz, 1923; Bertoni, [1927] 
2008; Bertoni, [1940] 2010; Storni, 1944; Cadogan, 1955; Gatti, 1985; Arenas, 1997; González Torres, 2003). En la lámina 118 donde el tabaco se halla ilustrado, se cita un "tabaco silvestre" "al cual llaman coro en lengua del Cuzco, y que aquí entre los Indios petízaete...”. Este último, según lo han referido numerosos autores (Martínez Crovetto, 1978; Martínez Crovetto, 1980; Scarpa et Rosso, 2011), corresponde de manera unívoca -al menos para el nordeste argentino- a Nicotiana paa Mart. Crov.

"Caaímbé" (lámina 122): Tanto la descripción del texto como la ilustración de la lámina hacen referencia a un típico representante del género Valeriana. Según las citas bibliográficas de Gatti (1985) y De la Peña et Pensiero (2004) podría tratarse de $V$. scandens L., taxón al que es referido el nombre vulgar completo "caáimbé mirí" y que vegeta silvestre en la región de las misiones.

"Consuelda mayor indica" (lámina 126): Coincidimos con González Torres (2003) que se trata de Spermacoce verticillata L., ya que además de su correspondencia con el nombre vulgar referido, coincide el aspecto general de la planta ilustrado en la lámina y sus hojas típicamente verticiladas. Asimismo, es de amplia distribución en toda el área de las antiguas misiones jesuíticas donde sus propiedades medicinales se hallan difundidas (González Torres, 2003; Flora Argentina, 2019).

"Cacaho" (lámina 129): No hay dudas que se trata de Theobroma cacao L., tanto por la descripción del texto, por la ilustración (tomado de la obra de Bonti "Mantissa Aromatica") como por la correspondencia botánica unívoca de su nombre vulgar en la bibliografía (Martius, 1843; Montesano Delchi, 1913; Dimitri, 1980).

"Canela" (lámina 131): Las dos especies nativas al área de acción jesuítica a las que se denomina de esta manera son Cinnamomum triplinerve (Ruiz \& Pav.) Kosterm.y $C$. riedelianum Kosterm. Sin embargo, solo la primera se ajusta a la descripción de la M.M.M. Asimismo, C. verum J. Presl, especie exótica naturalizada, también responde a la descripción -especialmente a las tres nervaduras marcadas en sus hojas, su morfología así como al color de sus flores-y también es llamada "canela" en el área según Martius (1843), Montesano Delchi (1913), González Torres (2003), Basualdo et al. (2004); Delucchi et al. (2016). La temprana cita de Martius permitiría inferir que también podría tratarse de esta especie.

“Árbol del clavo" (lámina 132): No habría dudas acerca de la identidad botánica de esta planta como Sysygium aromaticum (L.) Merr. \& L. M. Perry ya que explícitamente se indica que "es el verdadero clavo que nos trahená vender del Oriente". Las correspondencias botánicas que citan sus usos medicinales (Montesano Delchi, 1913; Dimitri, 1980; González Torres, 2003) coinciden también con esta determinación.

Por último, algunas de estas plantas participan con otras en remedios mixtos, entre las que se cuenta la "ruda" y a la "manzanilla", plantas cuya identidad botánica resulta muy conocida desde antaño (Ruta chalepensis L. y Matricaria chamomilla L., respectivamente).

\section{Interpretación de las categorías gnoseológicas}

A partir del empleo de bibliografía acerca de la medicina y de la botánica médica histórica antes citada, pudimos interpretar con cierta precisión las indicaciones terapéuticas a los que aludían las categorías gnoseológicas referidas por su denominación popular, la mayoría de las cuales han caído en desuso o bien fueron reemplazadas por terminología médica específica. De esta manera, interpretamos las correspondencias entre las siguientes expresiones del texto de la M.M.M. -que se transcriben a continuación entre comillas-y las indicaciones terapéuticas a las que harían referencia:

- Abortivo: "para desopilar la matriz" y para que "no se echen a mugeres preñadas porque malparen";

- Afrodisíaco: "fortalece á los recien casados y provoca á lujuria" y "dispierta la virtud genital";

- Anafrodisíaco masculino: "hace bajar la cabeza del instrumento de la deshonestidad 
y mitiga sus pasiones", refiriéndose obviamente al pene;

- Anafrodisíaco femenino: "reprime flujos de las hembras y sus furores uterinos";

- Antiemenagogo: "retiene el flujo de sangre llubia, y menstruo", "flusion de sangre menstrua inmodica por boca de la madre" y "ataja el flujo del menstruo inmodico";

- Antisifilítico: "contra el mal francés", "humores gálicos" y "gálico";

- Antigalactorreico: "los pechos endurecidos los relaja, y resuelve la demasiada leche";

- Contra la espermatorrea y antigonorreico: "retener el flujo de orina y semen ó purgaciones blancas". Según Venegas (1788) las "purgaciones blancas" de los hombres eran un síntoma de la gonorrea;

- Emenagogo "provoca el menstruo", "para retenciones de menstruo" y "para la retencion de los meses";

- Oxitócico: "descarga la matriz de las mugeres", "echar a la criatura, las pares, y sangre retenida" y "acelera o provoca el parto";

- Rejuvenecimiento vaginal: "pasar por vírgenes las que cayeron en flaqueza de carne";

- Vivificante: "a los recien casados, que por exceso se van secando y consumiendo, apartandololos por algunos dias de sus mugeres"; "curó en Madrid á cierto mozo desustanciado de mugeres".

Respecto a la "hipocondría menárquica", solo pudimos interpretar sobre la base de consulta a las obras históricas citadas que se trata de una afección de naturaleza psicosomática o nerviosa propia de mujeres menarcas con diversos síntomas en la zona ventral.

\section{Análisis estadístico de los datos}

Como resultado de analizar un total de 66 entidades vegetales sobre las cuales se asignan un total de 101 indicaciones terapéuticas referidas al aparato reproductor (Scarpa et Anconatani, 2019), se ha podido identificar desde el punto de vista botánico un total de 57 taxa vegetales (48 de ellos hasta el nivel de especie y 9 a nivel de género botánico) sobre los que se consignan 102 datos etnobotánicos propiamente dichos.
En la Tabla 1 se listan los datos etnobotánicos obtenidos referentes al tratamiento de trastornos del aparato reproductor ordenados por familia botánica, indicando las partes empleadas y sus formas de preparación y/o administración en caso de haber sido estas referidas en la fuente primaria de los datos.

Las principales indicaciones terapéuticas referidas para trastornos del aparato reproductor son los emenagogos, oxitócicos, antisifilíticos, afrodisíacos, antigononorreicos, antiemenagogos, contra la espermatorrea, para el rejuvenecimiento vaginal, abortivos, anafrodisíacos masculinos, anafrodisíaco femenino, vivificantes, esterilizantes, antigalactorreicos y contra la "hipocondría menárquica". En la Figura 2 se grafican los valores de cada una de estas aplicaciones específicas de las plantas.

Entre las familias botánicas más representadas figuran las Asteráceas (con 12 datos), Lamiáceas (11), Burseráceas (8), Amarantáceas y Fabáceas (con 6 cada una), Pasifloráceas (5) y Anacardiáceas, Lauráceas, Malváceas, Pontederiáceas y Solanáceas (con 4 datos cada una). Entre los taxa botánicos con mayor cantidad de datos figuran Protium heptaphyllum y Protium sp. (con 4 datos cada una); Cantinoa mutabilis, Condea undulata, Coronopus didymus, Dysphania ambrosioides, Hypis lorentziana, Inula helenium, Matricaria chamomilla, Myrocarpus frondosus, Parthenium hysterophorus, Passiflora caerulea y Ruta chalepensis (con 3 datos cada una).

Del total de taxa empleados contra afecciones del aparato reproductor se indica que el $60 \%$ son caracterizados como "cálidos", el 58\% como "secos", 15\% como "húmedos" y $13 \%$ como "fríos" (en distintos grados de intensidad).

En la Tabla 2 se efectúa una comparación entre las cantidades absolutas y relativas de los taxa y usos referidos contra trastornos del aparato reproductor en la M.M.M. y los citados en trabajos sobre etnobotánica médica folk de zonas aledañas a las misiones donde actuó P. Montenegro, esto es, sudeste de Brasil, Paraguay y nordeste de Argentina. Las plantas y usos medicinales compartidos con dichas obras fueron de $42,1 \%$ y de $5,8 \%$ en promedio, respectivamente. 
Tabla 1. Usos medicinales de las plantas contra trastornos del aparato reproductor en la Materia Médica Misionera. Referencias: CO: Corteza; Dec.: Decocción; FL: Flores; FR: Fru; HO: Hoja; Inf.: Infusión; Int. (ingerido); PA: Parte aérea; RA: Raíz; SE: Semillas; TA: Tallo.

Table 1. Medicinal uses of plants against the disorders of reproductive system in the Materia Médica Misionera.

References: CO: Bark; Dec.: Decoction; FL: Flowers; FR: Fruits; HO: Leaves; Inf.: Infusion; Int. (ingested); PA: Aerial part; RA: Roots; SE: Seeds; TA: Stems.

\begin{tabular}{|c|c|c|}
\hline $\begin{array}{l}\text { Familia botánica y } \\
\text { nombre científico }\end{array}$ & Nombre vulgar y lámina M.M.M. & Preparación y aplicación específica \\
\hline \multicolumn{3}{|l|}{ AMARANTHACEAE } \\
\hline $\begin{array}{l}\text { Amaranthus sp. } \\
\text { Amaranthus viridis L. }\end{array}$ & $\begin{array}{l}\text { Caarurú morotí macho y hembra } \\
\text { (lám. 59) }\end{array}$ & $\begin{array}{l}\text { El polvo de la corteza de su raíz en } \\
\text { aceite es aplicado vía vaginal como } \\
\text { oxcitócico }\end{array}$ \\
\hline $\begin{array}{l}\text { Dysphania ambrosioides } \\
\text { (L.) Mosyakin y } \\
\text { Clemants }\end{array}$ & $\begin{array}{l}\text { Caané guazú, } \\
\text { Payco, } \\
\text { Lepidio (lám. 53) }\end{array}$ & $\begin{array}{l}\text { Dec. en vino de sus } \mathrm{HO}, \mathrm{CO} \text { y } \mathrm{SE} \text { y } \\
\text { de parte aérea de Ruta chalepensis o } \\
\text { Matricaria chamomilla molidos en vahos } \\
\text { y enjuagues vaginales como oxcitócico, } \\
\text { abortivo, emenagogo }\end{array}$ \\
\hline $\begin{array}{l}\text { Pfaffia glomerata } \\
\text { (Spreng.) Pedersen }\end{array}$ & $\begin{array}{l}\text { Caá pari miri, } \\
\text { Batatilla de Don Antonio (lám. 103) }\end{array}$ & $\begin{array}{l}\text { Dec. de su RA con azúcar o miel es } \\
\text { oxcitócico }\end{array}$ \\
\hline \multicolumn{3}{|l|}{ ANACARDIACEAE } \\
\hline $\begin{array}{l}\text { Schinus areira L. } \\
\text { Schinus molle L. }\end{array}$ & $\begin{array}{l}\text { Molle de Castilla, Lentisco blanco, } \\
\text { Aguaraí guazú (lám. 49) }\end{array}$ & $\begin{array}{l}\text { Su resina en el agua de bebida o } \\
\text { bien un bálsamo preparado con } \\
\text { sus HO molidas se ingiere contra la } \\
\text { espermatorrea y como antigonorreico }\end{array}$ \\
\hline $\begin{array}{l}\text { Schinus terebinthifolius } \\
\text { Raddi }\end{array}$ & $\begin{array}{l}\text { Aguaraĭbaĭ miri, Aguaraíbaí } \\
\text { Lentisco negro } \\
\text { Molle negro (lám. 50) }\end{array}$ & $\begin{array}{l}\text { Su RA molida en algodón empapado se } \\
\text { introduce en la boca de la matriz como } \\
\text { antiemenagogo. También desleído en } \\
\text { zumo de llantén }\end{array}$ \\
\hline \multicolumn{3}{|l|}{ APOCYNACEAE } \\
\hline $\begin{array}{l}\text { Asclepias mellodora A. } \\
\text { St.-Hil. }\end{array}$ & $\begin{array}{l}\text { Mboy caá, Yerba de colmillo de } \\
\text { vivora (lám. 44) }\end{array}$ & $\begin{array}{l}\text { Dec. Int. de sus HO se usa contra la } \\
\text { hipocondría menárquica }\end{array}$ \\
\hline \multicolumn{3}{|l|}{ ARACEAE } \\
\hline $\begin{array}{l}\text { Alpinia officinarum } \\
\text { Hance }\end{array}$ & Galanga (s/lám.) & $\begin{array}{l}\text { Su RA molida disuelta en vino blanco } \\
\text { o su dec. se usa como afrodisíaco y } \\
\text { vivificante }\end{array}$ \\
\hline $\begin{array}{l}\text { Philodendron } \\
\text { bipinnatifidum Schott ex } \\
\text { Endl. }\end{array}$ & Guembeǐ (lám. 69) & $\begin{array}{l}\text { La ingestión de las moscas que se } \\
\text { crían en sus lenticelas es afrodisíaco }\end{array}$ \\
\hline \multicolumn{3}{|l|}{ ARAUCARIACEAE } \\
\hline $\begin{array}{l}\text { Araucaria angustifolia } \\
\text { (Bertol.) Kuntze }\end{array}$ & Curi î (lám. 79) & $\begin{array}{l}\text { El polvo de su resina desecada } \\
\text { sahumado e inhalado es emenagogo }\end{array}$ \\
\hline \multicolumn{3}{|l|}{ ASTERACEAE } \\
\hline Inula helenium L. & $\begin{array}{l}\text { Enula campana, } \\
\text { Caapé (lám. 114) }\end{array}$ & $\begin{array}{l}\text { Dec. de la RA seca y puesta en miel } \\
\text { o arrope es afrodisíaco, emenagogo y } \\
\text { oxcitócico }\end{array}$ \\
\hline Matricaria chamomilla L. & Manzanilla (s/lam.) & $\begin{array}{l}\text { Dec. de su parte aérea en vino junto } \\
\text { a } \mathrm{HO}, \mathrm{CO} \text { y SE de } D \text {. ambrosioides } \\
\text { molidos en vahos y enjuagues } \\
\text { vaginales como oxcitócico, abortivo, } \\
\text { emenagogo }\end{array}$ \\
\hline
\end{tabular}




\begin{tabular}{|c|c|c|}
\hline $\begin{array}{l}\text { Familia botánica y } \\
\text { nombre científico }\end{array}$ & Nombre vulgar y lámina M.M.M. & Preparación y aplicación específica \\
\hline $\begin{array}{l}\text { Parthenium } \\
\text { hysterophorus L. }\end{array}$ & $\begin{array}{l}\text { Artemisa, } \\
\text { Sandía rogue miri (lám. 57) }\end{array}$ & $\begin{array}{l}\text { Dec. Int. de su PA con la de Coronopus } \\
\text { didymus es afrodisíaco, emenagogo y } \\
\text { oxcitócico }\end{array}$ \\
\hline $\begin{array}{l}\text { Schkuhria pinnata } \\
\text { (Lam.) Kuntze ex Thell. }\end{array}$ & Canchalagua, Capií iropitá (lám. 40) & $\begin{array}{l}\text { Dec. de su PA es Int. como emenagogo } \\
\text { y oxcitócico }\end{array}$ \\
\hline Tagetes spp. & Añangapirĭ - cáa (lám. 41) & Dec. de su PA Int. es antigonorreico \\
\hline \multicolumn{3}{|l|}{ BIGNONIACEAE } \\
\hline $\begin{array}{l}\text { Cybistax antisyphilitica } \\
\text { (Mart.) Mart. }\end{array}$ & Caaroba (lám. 84) & $\begin{array}{l}\text { La Dec. de sus } \mathrm{HO} \text { o FI y piedra bezoar } \\
\text { ingerida es antisifilitico }\end{array}$ \\
\hline Jacaranda spp. & $\begin{array}{l}\text { Parápará î (lám. 81) } \\
\text { San Antonino }\end{array}$ & $\begin{array}{l}\text { La Dec. de su CO o TA ingerida es } \\
\text { antisifilítico }\end{array}$ \\
\hline \multicolumn{3}{|l|}{ BRASSICACEAE } \\
\hline $\begin{array}{l}\text { Coronopus didymus (L.) } \\
\text { Sm. }\end{array}$ & Mastuerzo indico (lám. 36) & $\begin{array}{l}\text { Dec. Int. con } P \text {. hysterophorus es } \\
\text { afrodisíaco y emenagogo. Int. como } \\
\text { alimento es oxcitócico }\end{array}$ \\
\hline \multicolumn{3}{|l|}{ BURSERACEAE } \\
\hline $\begin{array}{l}\text { Protium heptaphyllum } \\
\text { (Aubl.) Marchand } \\
\text { Protium sp. }\end{array}$ & $\begin{array}{l}\text { Ibirá ysy (negro), Arbol del gumi } \\
\text { elemi } \\
\text { lbirá ysy (blanco)(lám. 3) }\end{array}$ & $\begin{array}{l}\text { Su resina es ingerida como abortivo, } \\
\text { emenagogo, antigonorreico y contra } \\
\text { espermatorrea }\end{array}$ \\
\hline \multicolumn{3}{|l|}{ CAPRIFOLIACEAE } \\
\hline $\begin{array}{l}\text { Valeriana cf. Scandens } \\
\text { L. }\end{array}$ & Caaímbé (lám. 122) & $\begin{array}{l}\text { Dec. Int. de su RA es emenagogo y } \\
\text { oxcitócico }\end{array}$ \\
\hline \multicolumn{3}{|l|}{ CONVOLVULACEAE } \\
\hline Ipomoea sp. & $\begin{array}{l}\text { Purga criolla, corregüela, } \\
\text { Yetirá baí (lám. 18) }\end{array}$ & $\begin{array}{l}\text { La pulpa de sus FR machacados } \\
\text { Int. con azúcar en almirez más el } \\
\text { agregado de "sen" (sin identificar) como } \\
\text { antisifilítico }\end{array}$ \\
\hline \multicolumn{3}{|l|}{ CYPERACEAE } \\
\hline $\begin{array}{l}\text { Cyperus sesquiflorus } \\
\text { (Torr.) Mattf. \& Kük. }\end{array}$ & $\begin{array}{l}\text { Esquinanto menor, } \\
\text { Capi'í catí (lám. 28) }\end{array}$ & $\begin{array}{l}\text { Dec. de su FL o RA con azúcar o miel } \\
\text { Int. como emenagogo }\end{array}$ \\
\hline \multicolumn{3}{|l|}{ DIOSCOREACEAE } \\
\hline Dioscorea sinuata Vell. & $\begin{array}{l}\text { Carachí blanco, Pan de puerco, } \\
\text { pan porcino o Ciclamino (lám. 48) }\end{array}$ & $\begin{array}{l}\text { Sus tubérculos Int. o (su dec.?) } \\
\text { embebidos en algodón son aplicados } \\
\text { vía vaginal como emenagogo o atado } \\
\text { al muslo izquierdo como oxcitócico }\end{array}$ \\
\hline \multicolumn{3}{|l|}{ EUPHORBIACEAE } \\
\hline Croton urucurana Baill. & $\begin{array}{l}\text { Sangre de Drago, } \\
\text { Ibirá caáberá (lám. 68) }\end{array}$ & $\begin{array}{l}\text { Con su resina se embeben algodones } \\
\text { que se aplican vía vaginal como } \\
\text { antiemenagogo }\end{array}$ \\
\hline Euphorbia sp. & $\begin{array}{l}\text { Caá cambí (curií), xalapa, lechetrez } \\
\text { (lám. 51) }\end{array}$ & $\begin{array}{l}\text { Su RA molida macerada en vino Int. } \\
\text { como antisifilítico }\end{array}$ \\
\hline Ricinus communis $\mathrm{L}$. & Recino arbol (lám. 82) & $\begin{array}{l}\text { Sus } \mathrm{HO} \text { calentadas o mojadas } \\
\text { en vinagre se aplican de manera } \\
\text { tópica sobre las mamas como } \\
\text { antigalactorreico }\end{array}$ \\
\hline
\end{tabular}




\begin{tabular}{|c|c|c|}
\hline $\begin{array}{l}\text { Familia botánica y } \\
\text { nombre científico }\end{array}$ & Nombre vulgar y lámina M.M.M. & Preparación y aplicación específica \\
\hline \multicolumn{3}{|l|}{ FABACEAE } \\
\hline $\begin{array}{l}\text { Libidibia paraguariensis } \\
\text { (D. Parodi) G. P. Lewis }\end{array}$ & $\begin{array}{l}\text { Guayacán } \\
\text { lbirá ehé (lám. 7) }\end{array}$ & $\begin{array}{l}\text { Con astillas de su CO con "aristolochia } \\
\text { rotundo femenina" (sin identificar) se } \\
\text { prepara una Inf. Int. como antisifilítico }\end{array}$ \\
\hline $\begin{array}{l}\text { Copaifera langsdorffii } \\
\text { Desf. }\end{array}$ & $\begin{array}{l}\text { Cupaĭ } \\
\text { Copayba (lám. 77) }\end{array}$ & $\begin{array}{l}\text { Su resina agregada a la dec. de } \\
\text { Plantago tomentosa se ingiere como } \\
\text { emenagogo }\end{array}$ \\
\hline Crotalaria incana L. & Toro caá (lám. 56) & Dec. de sus HO Int. es emenagogo \\
\hline $\begin{array}{l}\text { Myrocarpus frondosus } \\
\text { Allemão }\end{array}$ & $\begin{array}{l}\text { Anguaí, Arbol del Menjui, Ibira- } \\
\text { payé, Copal Calaminta (lám. 2) }\end{array}$ & $\begin{array}{l}\text { Dec. de su PA Int. con miel es } \\
\text { antigonorreico, antisifilítico y } \\
\text { emenagogo }\end{array}$ \\
\hline \multicolumn{3}{|l|}{ LAMIACEAE } \\
\hline \multirow{2}{*}{$\begin{array}{l}\text { Cantinoa mutabilis } \\
\text { (Rich.) Harley \& J.F.B. } \\
\text { Pastore } \\
\text { Condea undulata } \\
\text { (Schrank) Harley \& } \\
\text { J.F.B. Pastore } \\
\text { Hyptis lorentziana O. } \\
\text { Hoffm. }\end{array}$} & $\begin{array}{l}\text { Caaberá caá (caaberá guazú pucú), } \\
\text { dictamo blanco (lám. 112-113) }\end{array}$ & $\begin{array}{l}\text { Dec. de su PA Int. o en inhalaciones } \\
\text { como oxcitócico y afrodisíaco }\end{array}$ \\
\hline & & $\begin{array}{l}\text { Su RA junto a la de Spermacoce } \\
\text { verticillata, alumbre y "caparrosa" (sin } \\
\text { identificar) y RA de Passiflora spp. en } \\
\text { lavativas e hisopado de matriz con } \\
\text { algodón, se emplea para lograr el } \\
\text { rejuvenecimiento vaginal }\end{array}$ \\
\hline Glechon ciliata Benth. & $\begin{array}{l}\text { Tamanduaí miri, calaminta mirí } \\
\text { (lám. 86) }\end{array}$ & $\begin{array}{l}\text { Sus HO molidas se introducen en la } \\
\text { "boca de la matriz" como abortivo y } \\
\text { emenagogo }\end{array}$ \\
\hline \multicolumn{3}{|l|}{ LAURACEAE } \\
\hline $\begin{array}{l}\text { Cinnamomum triplinerve } \\
\text { (Ruiz \& Pav.) Kosterm. } \\
\text { Cinnamomum verum J. } \\
\text { Presl }\end{array}$ & Canela (lám. 131) & $\begin{array}{l}\text { Dec. de su CO? sería emenagogo y } \\
\text { oxcitócico }\end{array}$ \\
\hline \multicolumn{3}{|l|}{ MALVACEAE } \\
\hline $\begin{array}{l}\text { Sidastrum paniculatum } \\
\text { (L.) Fryxell }\end{array}$ & $\begin{array}{l}\text { Yerba de la víbora, macaguá caá } \\
\text { (lám. 109) }\end{array}$ & $\begin{array}{l}\text { Dec. de sus HO Int. es emenagogo y } \\
\text { oxcitócico }\end{array}$ \\
\hline Theobroma cacao L. & Cacaho: (lám. 129) & $\begin{array}{l}\text { Sus granos pisados y molidos se } \\
\text { ingieren como emenagogo y oxcitócico }\end{array}$ \\
\hline \multicolumn{3}{|l|}{ MORACEAE } \\
\hline $\begin{array}{l}\text { Dorstenia brasiliensis } \\
\text { Lam. }\end{array}$ & $\begin{array}{l}\text { Contrayerba o taropé femenina y } \\
\text { masculina (lám. 38-39) }\end{array}$ & $\begin{array}{l}\text { Dec. de su RA Int. con miel es } \\
\text { emenagogo y oxcitócico }\end{array}$ \\
\hline \multicolumn{3}{|l|}{ MYRTACEAE } \\
\hline $\begin{array}{l}\text { Psidium guajava L. } \\
\text { Psidium spp. }\end{array}$ & $\begin{array}{l}\text { Arazá, guayabas. hezaé tibaé, } \\
\text { guayaba campesina (lám. 11-12) }\end{array}$ & $\begin{array}{l}\text { Dec. de sus } \mathrm{HO} \text { Int. y en lavajes } \\
\text { o enemas por via vaginal es } \\
\text { antiemenagogo }\end{array}$ \\
\hline $\begin{array}{l}\text { Syzygium aromaticum } \\
\text { (L.) Merr. \& L. M. Perry }\end{array}$ & Árbol del clavo (lám. 132) & $\begin{array}{l}\text { Dec. de sus FI Int. o aplicado por via } \\
\text { vaginal es emenagogo }\end{array}$ \\
\hline
\end{tabular}




\begin{tabular}{|c|c|c|}
\hline $\begin{array}{l}\text { Familia botánica y } \\
\text { nombre científico }\end{array}$ & Nombre vulgar y lámina M.M.M. & Preparación y aplicación específica \\
\hline \multicolumn{3}{|l|}{ OXALIDACEAE } \\
\hline Oxalis sp. & $\begin{array}{l}\text { Acetosa (o acedera) mayor, } \\
\text { oxilapato, romaza (lám. 20) }\end{array}$ & $\begin{array}{l}\text { Destilado de sus } \mathrm{HO} \text { y RA en } \\
\text { un mezcla de agua y vino Int. es } \\
\text { emenagogo }\end{array}$ \\
\hline \multicolumn{3}{|l|}{ PASSIFLORACEAE } \\
\hline \multirow[t]{2}{*}{ Passiflora caerulea L. } & $\begin{array}{l}\text { Mburucuyá amarillo silvestre (lám. } \\
\text { 16) }\end{array}$ & $\begin{array}{l}\text { Dec. de RA Int. es antisifilítico. Esta } \\
\text { última con RA de } C \text {. mutabilis; } C \text {. } \\
\text { undulata o } H \text {. lorentziana, más alumbre } \\
\text { y "caparrosa" en lavativas o embebido } \\
\text { en algodón se aplica por vía genital } \\
\text { para rejuvenecimiento vaginal }\end{array}$ \\
\hline & & Dec. de su CO Int. es antiemenagogo \\
\hline Passiflora edulis Sims & $\begin{array}{l}\text { Granadilla de la pasión amarilla } \\
\text { (lám. 15) }\end{array}$ & Dec. de RA Int. es antisifilítico. \\
\hline Passiflora spp. & Granadilla de la pasión (lám. 14) & $\begin{array}{l}\text { Dec. de su RA junto a Smilax } \\
\text { campestris y Gonopterodendron } \\
\text { sarmientoi Int. es como antisifilítico }\end{array}$ \\
\hline \multicolumn{3}{|l|}{ PLANTAGINACEAE } \\
\hline $\begin{array}{l}\text { Plantago tomentosa } \\
\text { Lam. }\end{array}$ & $\begin{array}{l}\text { Llantén silvestre peludo, caá yuquí } \\
\text { (lám. 26) }\end{array}$ & $\begin{array}{l}\text { Su PA machacada y filtrada se ingiere } \\
\text { como antiemenagogo. La dec. con } \\
\text { resina "cupaî" Int. es emenagogo }\end{array}$ \\
\hline \multicolumn{3}{|l|}{ PONTEDERIACEAE } \\
\hline $\begin{array}{l}\text { Pontederia crassipes } \\
\text { Mart. } \\
\text { Pontederia rotundifolia } \\
\text { L. f. }\end{array}$ & Aguapé, aguapé guazú (lám. 30) & $\begin{array}{l}\text { Dec. de sus } \mathrm{HO}, \mathrm{FI} \text { o RA Int. es } \\
\text { anafrodisíaco (masculino y femenino) y } \\
\text { antigonorreico }\end{array}$ \\
\hline \multicolumn{3}{|l|}{ RUBIACEAE } \\
\hline $\begin{array}{l}\text { Spermacoce verticillata } \\
\text { L. }\end{array}$ & Consuelda mayor indica (lam. 126) & $\begin{array}{l}\text { Su RA con la de } C \text {. mutabilis, } \\
\text { C. undulata o } H \text {. lorentziana y } \\
\text { la de Passiflora spp., alumbre y } \\
\text { "caparrosa" en lavativas e hisopado } \\
\text { de matriz con algodón se emplea para } \\
\text { rejuvenecimiento vaginal }\end{array}$ \\
\hline \multicolumn{3}{|l|}{ RUTACEAE } \\
\hline Ruta chalepensis L. & Ruda (s/lam.) & $\begin{array}{l}\text { Dec. de su PA en vino junto a } \mathrm{HO}, \mathrm{CO} \\
\text { y } \mathrm{SE} \text { de } D \text {. ambrosioides molidos en } \\
\text { vahos y enjuagues vaginales como } \\
\text { oxcitócico, abortivo, emenagogo }\end{array}$ \\
\hline \multicolumn{3}{|l|}{ SMILACACEAE } \\
\hline $\begin{array}{l}\text { Smilax campestris } \\
\text { Griseb. }\end{array}$ & $\begin{array}{l}\text { Raíz de la China Blanca, Yuá pecá } \\
\text { miri (yua pitá) (lám. 90-91) }\end{array}$ & $\begin{array}{l}\text { Dec. de su RA Int. es antisifilítico junto } \\
\text { con la de Passiflora spp. y astillas de } \\
\text { duramen de G. sarmientoi }\end{array}$ \\
\hline \multicolumn{3}{|l|}{ SOLANACEAE } \\
\hline $\begin{array}{l}\text { Nicotiana tabacum L. } \\
\text { Nicotiana paa Mart. } \\
\text { Crov. }\end{array}$ & $\begin{array}{l}\text { Tabaco (lám. 118) } \\
\text { Coro, caá coró (s/lám.) }\end{array}$ & $\begin{array}{l}\text { Su RA mascada se emplea como } \\
\text { emenagogo y oxcitócico }\end{array}$ \\
\hline
\end{tabular}




\begin{tabular}{|l|l|l|}
\hline $\begin{array}{l}\text { Familia botánica y } \\
\text { nombre científico } \\
\text { ZYGOPHYLLACEAE }\end{array}$ & Nombre vulgar y lámina M.M.M. & Preparación y aplicación específica \\
\hline $\begin{array}{l}\text { Gonopterodendron } \\
\text { sarmientoi (Lorentz ex } \\
\text { Griseb.) A. C. Godoy- } \\
\text { Bürki }\end{array}$ & $\begin{array}{l}\text { Palo santo guaycurú, resinoso o } \\
\text { aromático (s/lam.) }\end{array}$ & $\begin{array}{l}\text { La infusión de astillas de su duramen } \\
\text { con RA de "Passiflora spp." y de S. } \\
\text { campestris se ingiere como antisifilítico }\end{array}$ \\
\hline
\end{tabular}

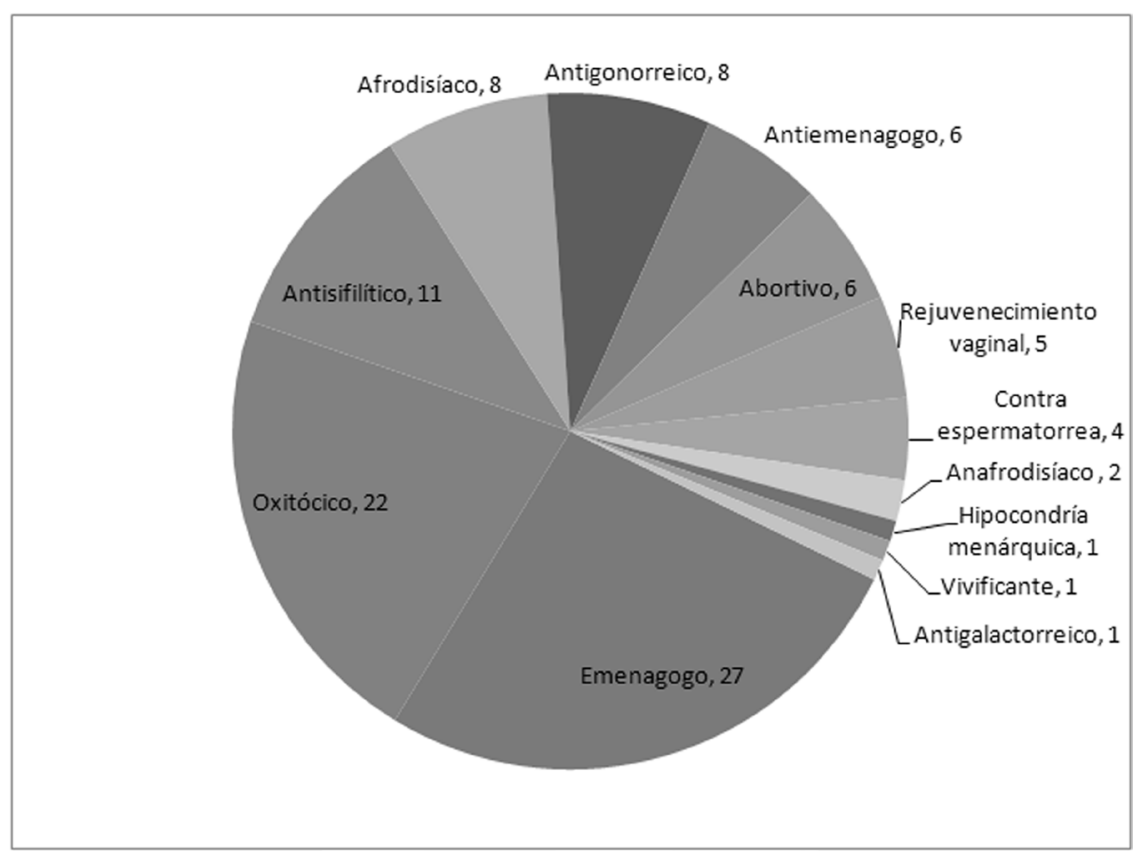

Fig. 2. Aplicaciones de las plantas contra trastornos del sistema reproductor.

Fig. 2. Applications of plants against disorders of the reproductive system.

Tabla 2. Taxa vegetales y usos medicinales compartidos con etnobotánicas médicas aledañas a las misiones.

Table 2. Plant taxa and medicinal uses shared with medical ethnobotany adjacent to the missions.

\begin{tabular}{|lccccc|}
\hline & $\begin{array}{c}\text { \# Taxa } \\
\text { compartidos }\end{array}$ & $\begin{array}{c}\text { \% taxa } \\
\text { M.M.M. comp. }\end{array}$ & $\begin{array}{c}\text { \# Usos } \\
\text { compartidos }\end{array}$ & $\begin{array}{c}\text { \% Usos } \\
\text { M.M.M. comp. }\end{array}$ & $\begin{array}{c}\text { \# Usos comp. } \\
\text { / taxa comp. }\end{array}$ \\
$\begin{array}{l}\text { Gonzáles Torres (2003; } \\
\text { Folk Paraguay) }\end{array}$ & 40 & 70,18 & 22 & 22 & 0,55 \\
$\begin{array}{l}\text { Pio Correa (1926; Folk } \\
\text { Brasil) }\end{array}$ & 6 & 10,53 & 2 & 2 & 0,33 \\
$\begin{array}{l}\text { Scarpa \& Anconatani } \\
\text { (2017, Etnobot. médica } \\
\text { misionera) }\end{array}$ & 19 & 33,33 & 5 & 5 & 0,26 \\
$\begin{array}{l}\text { Basualdo et al. (2004, } \\
\text { Folk Paraguay) }\end{array}$ & 24 & 42,11 & 3 & 3 & 0,13 \\
$\begin{array}{l}\text { Martínez Crovetto } \\
\text { (1981, Folk Corrientes) }\end{array}$ & 30 & 52,63 & 3 & 3 & 0,1 \\
$\begin{array}{l}\text { Martínez Crovetto† } \\
(2012, \text { Mbya Misiones) }\end{array}$ & 25 & 43,86 & 0 & 0 & 0 \\
\hline
\end{tabular}




\section{Discusión y Conclusiones}

Resulta significativo que, a pesar de los 300 años transcurridos, la proporción de remedios vegetales aplicados como emenagogos y oxitócicos (en conjunto 48\%, 49 datos) sea del todo similar a la registrada en trabajos actuales sobre etnobotánica médica criolla referidos al aparato reproductor (Martínez Crovetto, 1981 y Scarpa, 2004a). En cambio, las referencias a indicaciones terapéuticas para combatir enfermedades venéreas (gonorrea, sífilis, etc.) en la M.M.M. $-19 \%$ de los datosson claramente mayores que en la actualidad, aunque similar a la evidenciada en trabajos sobre etnobotánica histórica correspondientes al siglo XIX (Scarpa et al., 2016) y de comienzos y fines del siglo XX (Scarpa et Anconatani, 2017; Scarpa et Rosso, 2019). Esta diferencia con los datos actuales radicaría en las profundas transformaciones sufridas en el estado sanitario de la población desde ese entonces a la actualidad, producto de la aplicación de modernas prácticas preventivas y terapéuticas que habrían disminuido considerablemente tales enfermedades (sífilis, gonorrea, etc.). Otras divergencias sustanciales entre las indicaciones terapéuticas de las plantas registradas en la M.M.M. y las actuales, son los usos referidos para el rejuvenecimiento vaginal, como afrodisíacos y anafrodisíacos -tanto masculinos como femeninos-, contra la espermatorrea, la "hipocondría menárquica", los esterilizantes y "vivificantes", todos los cuales resultan hoy prácticamente inexistentes -o muy raros-.

Las diferencias antes evidenciadas explicarían la escasa cantidad de plantas y de usos medicinales compartidos entre la M.M.M. y los referidos en obras actuales (Tabla 2), de lo cual se infiere el alto nivel de originalidad de los datos etnobotánicos identificados en este trabajo. Una excepción a esto último lo constituye las similitudes halladas entre los datos publicados por González Torres (2003) y la M.M.M. respecto -sobre todo- a la proporción de plantas medicinales comunes entre ambas obras $(70,18 \%)$ (aunque no tanto en las aplicaciones médicas de las mismas de tan solo 22\%). Estos datos, así como el alto valor del cociente entre usos medicinales comunes por taxón compartido se explicarían debido a que el trabajo de González Torres (2003) incluye una compilación de usos medicinales de las plantas por la población criolla del Paraguay tanto actuales como históricos (a diferencia de las otras obras consideradas en la comparación). En suma, se puede concluir que estos resultados indicarían una estrecha vinculación entre la M.M.M. y la conformación de la etnobotánica criolla actual del Paraguay, aunque no del Brasil -sensu Pío Correa, 1926- ni del nordeste de Argentina.

Destaca por su originalidad que las especies más representadas sean del género Protium (P. heptaphyllum y Protium spp.), ya que estas no aparecen indicadas en la actualidad contra trastornos del aparato reproductor en un estudio especializado sobre la etnobotánica de este género para la misma zona (Arenas, 2007), ni en otras obras de etnobotánica médica (Martínez Crovetto, 1981) o folklórica del área (González Torres, 2003).

El elevado empleo de plantas caracterizadas como "cálidas" (60\%) para dolencias del aparato reproductor resulta congruente con el tipo de etiología ("fría") asignada a la mayoría de estos tipos de trastornos en la medicina humoral latinoamericana en general (Kay, 1976) y de los criollos de Argentina en particular (Scarpa, 2004b; Martínez, 2010). De esta manera, se constata que el criterio terapéutico al que responden estas prescripciones se corresponde con el principio de oposición hipocrático-galénico. Asimismo, se destaca la alta participación (58\%) de remedios categorizados como "secos" (o "secantes") la cual, como categoría humoral, se hallaría aparentemente desaparecida en la actualidad (Foster, 1979; Scarpa, 2004b).

Las coincidencias registradas aquí entre la M.M.M. y la etnobotánica médica criolla de la actualidad estarían indicando cierto grado de continuidad entre ambas medicinas, no solo en cuanto a la farmacopea utilizada sino también respecto a criterios etiológico-terapéuticos compartidos. Esto mismo fue registrado por Kay (1976) en Norteamérica para una materia médica y una época comparable a la que aquí se analiza (referida a la etnoginecología, fechada en 1711) escrita por el Padre Esteyneffer jesuita de Nuevo México- titulada "Florilegio 
Medicinal". En efecto, su análisis concluye que los remedios prescriptos en dicha obra contra trastornos del aparato reproductor femenino serían el producto de una fusión entre la etnomedicina indígena (Utoazteca de las etnias Papago, Pima, Yaqui, Paipai, Tarahumara y Tepehuan) y la europea. Todo ello permitiría concluir aquí, al igual que lo registrado para misiones jesuíticas del Amazonas brasileño durante el siglo XVIII (Domingues et Machado dos Santos, 2007), que las mismas habrían actuado como espacios de mestizaje entre los acervos indígenas de varios grupos étnicos y el de los europeos, cuyo producto habría contribuido a la conformación -en gran partede la etnobotánica médica de los actuales criollos de estas regiones.

En suma, se concluye que un total de 102 remedios vegetales asignados al aparato reproductor en la M.M.M. pudieron ser caracterizados como datos etnobotánicos propiamente dichos, al identificar desde el punto de vista botánico 57 taxa a los que estos aluden. Si bien solo se pudieron identificar $57 \mathrm{de}$ las 66 entidades vegetales cuyo uso medicinal contra el aparato reproductor fue referido en el antecedente principal a este trabajo (Scarpa et Anconatani, 2019), el número total de aplicaciones medicinales halladas (102) resulta similar al estimado en dicho trabajo (101) debido a que para varias "entidades vegetales"-en su momento incógnitas- se han identificado en este trabajo más de un taxón, lo cual incrementa de por sí el número de datos etnobotánicos totales obtenidos por entidad vegetal que pudo ser identificada.

Estos resultados constituyen la primera demostración del elevado valor que el análisis de esta fuente posee para la etnobotánica del Cono Sur, teniendo en cuenta que estos datos solo representan alrededor del 10\% del total registrado en la M.M.M. por Scarpa et Anconatani (2019) y la influencia que estos habrían tenido en la etnobotánica médica criolla actual. La categorización cálido-fresca y seco-húmedas de cada uno de los trastornos del aparato reproductor, así como de las plantas medicinales referidas, resultaría de gran utilidad para ulteriores interpretaciones de criterios terapéuticos de la medicina popular criolla perdidas en la actualidad.
Respecto a otros abordajes realizados sobre las identidades botánicas de las entidades vegetales mencionadas en la M.M.M. mencionados en este trabajo, consideramos aquí que aquellos que no tengan en cuenta categorías de índole etnomédico no deberían ser considerados de carácter "etnobotánico", en tanto no contextualizan los datos allí incluidos según el eje conceptual central al que responde dicha obra, es decir, el de la etnomedicina misionera.

\section{Agradecimientos}

A la Dra. Cintia Rosso y a las autoridades del Museo de Farmacobotánica "Juan A. Domínguez" de la Facultad de Farmacia y Bioquímica por habernos facilitado material empleado como fuente histórica en este trabajo. Al Consejo Nacional de Investigaciones Científicas y Técnicas y a la Universidad de Buenos Aires por financiarnos nuestra labor investigativa.

\section{Bibliografía}

Anconatani, L. M. \& Scarpa, G. F. (2015). Etnobotánica histórica de las Misiones Franciscanas del este de Formosa I: Hallazgos documentales de fuentes primarias, análisis crítico y comparación con la obra "Erbe medicinali del Chaco" de Franzè (1925). Dominguezia 31: 49-61.

Arenas, P. (1997). Nota introductoria al estudio del padre Franz Müller sobre la farmacopea guaraní. Parodiana 10: 189-196.

Arenas, P. (2007). Protium heptaphyllum (Burseraceae) en el folklore del Paraguay Oriental. Kurtziana 33: $7-26$.

Arrillaga de Maffei, B. (1969). Plantas medicinales. Ed. Nuestra Tierra, Montevideo.

Arrillaga de Maffei, B. (1977). Guía de plantas tóxicas. Ed. Universitaria de la República del Uruguay, Montevideo.

Basualdo, I., Soria N., Ortíz M. \& Degen, R. (2004). Plantas medicinales comercializadas en los mercados de Asunción y Gran Asunción. Parte I. Rojasiana 6: 95-114.

Bernardi, L. (1984). Contribución a la dendrología paraguaya. Boissiera 35: 120-271. 
Bertoni, M. ([1927] 2008). De la Medicina Guaraní. Etnografía sobre plantas medicinales. Ed. Buena Vista, Córdoba.

Bertoni, M. ([1940] 2010). Diccionario Botánico Latino - Guaraní y Guaraní - Latino con un Glosario de Vocablos y Elementos de la Nomenclatura Botánica. Introducción a "Las plantas usuales y útiles del Paraguay". Ministerio de Agricultura y Ganadería, República del Paraguay, Asunción.

Cadogan, L. (1955). Breve contribución al estudio de la nomenclatura guaraní en botánica. Boletín $\mathrm{n}^{\circ}$ 196. Ministerio de agricultura y ganadería-servicio técnico interamericano de cooperación agrícola, Asunción.

Cadogan, L. (1972). Ta-ngy puku. Aportes a la etnobotánica de algunas especies arbóreas del Paraguay Oriental. Suplemento antropológico 7: 7-59.

Campos Navarro, R. \& Scarpa, G. F. (2013). The cultural-bounddisease "empacho" in Argentina. A comprehensive botanico-historical and ethnopharmacological review. Journal of Ethnopharmacology 148: 349-360. https://doi.org/10.1016/j.jep.2013.05.002

Colmeiro, M. (1859). Manual completo de jardinería. Tomo II. Ed. C. López, Madrid.

Correa, R. F. (2003). El complejo de las "canchalaguas" en Argentina: Génesis, conformación y etnobotánica. Tesis doctoral presentada en la Facultad de Ciencias Naturales y Museo, Universidad Nacional de La Plata.

Crisci, J. V. \& Gancedo, O. A. (1971). Sistemática y etnobotánica del guembé ("Phylodendron bipinnatifidum") una importante aracea sudamericana. Revista del Museo de La Plata (Secc. Botánica) 11: 285-302.

Deckmann Fleck, E. C. D. (comp.) (2015). As artes de curar em um manuscrito jesuítico inédito do Setetecentos. O Paraguay Natural Ilustrado do Padre José Sánchez Labrador (1771-1776). Ed. Oikos, São Leopoldo.

Deckmann Fleck, E. C. D. \& Poletto, R. (2012). Circulação e produção de saberes e práticas científicas na América meridional no século XVIII: uma análise do manuscrito Materia médica misionera de Pedro Montenegro (1710). História, Ciências, Saúde 19: 1121-1138.

https://doi.org/10.1590/S0104-59702012000400002

De la Peña, M. R. \& Pensiero, J. F. (2004). Plantas Argentinas: Catálogo de nombres comunes. Ed. Lola, Buenos Aires.
Delucchi, D., Keller, H. A. \& Hurrell, J. A. (2016). Cinnamomum glanduliferum y C. verum (Lauraceae) naturalizadas en la Argentina. Bonplandia 25: 33-41. https://doi.org/10.30972/bon.2511269

Dimitri, M. J. (1980). Enciclopedia argentina de agricultura y jardinería, Tomo 1: Descripción de las plantas cultivadas. Ed. ACME, Buenos Aires.

Domingues, B. H. \& Machado Dos Santos, B. (2007). As missões jesuíticas naregião do Amazonas no século XVIII: um estudo de casos de mestiçagens. HistóriaUnisinos 11: 222-229.

Domínguez, J. A. (1928). Contribuciones a la materia médica argentina. Trabajos del Instituto de Botánica y Farmacología 44: 1-433. https://doi.org/10.5962/bhl.title.140290

Fiebrig-Gertz, C. (1923). Guarany names of paraguayan plants and animals. Revista del Jardín Botánico y Museo de Historia Natural del Paraguay 2: 105-149.

Flora Argentina. (2019). Base de datos Flora Argentina. The Andrew W. Mellon Foundation, IBODA, IMBIV, INTA. http://www.floraargentina.edu.ar/ [Consulta: Julio de 2019].

Flora del Cono Sur. (2019). Base de datos Flora del Cono Sur. The Andrew W. Mellon Foundation, IBODA, IMBIV, INTA. http://www.floraargentina.edu.ar/ [Consulta: Julio de 2019].

Foster, G. M. (1979). El legado hipocrático latinoamericano: "caliente" y "frío" en la medicina popular contemporánea. Medicina Tradicional 2: 5-19.

Freire, S. E. \& MolinA, A. M. (eds.). (2009). Flora Chaqueña-Argentina- (Formosa, Chaco y Santiago del Estero). Familia Asteraceae. INTA, Buenos Aires.

Gatтi, C. (1985). Enciclopedia Guaraní-Castellano de ciencias naturales y conocimientos paraguayos. Ed. Arte Nuevo, Asunción.

González Torres, D. M. (2003). Catálogo de Plantas Medicinales (y Alimenticias y Útiles) usadas en Paraguay. Ed. Servilibros, Asunción.

Hassler, E. (1909). Contribuciones a la flora del chaco argentino-paraguayo. Primera parte. Flórula pilcomayensis. Trabajos del Museo de Farmacología 21: $1-154$.

Hermida, M. C. \& Galli, M. C. (2019). Verde Chaco. [Blog]. Recuperado de: http://arbolesdelchaco. blogspot.com/

Hieronymus, J. ([1882] 1930). Plantas diafóricas. Flora Argentina. Ed. Atlántida, Buenos Aires.

Hurrell, J. A., Ulibarri, E. A., Delucchi, G. \& Pochettino, M. L. (2008). Biota Rioplatense XIII. Plantas aromáticas condimenticias. Ed. Lola, Buenos Aires. 
KAY, M. A. (1976). The fusión of Utoaztecan and european ethnogynecology in the florilegio medicinal. Actas del XLI Congreso Internacional de Americanistas 3: 323-330.

Keller, H. A. \& Pirondo A. (2012). Raúl N. Martínez Crovetto: los albores de la etnobotánica en la Argentina. Introducción a Estudios Etnobotánicos V. Bonplandia 21: 101-107. https://doi.org/10.30972/bon.2121281

Keller, H. A., Pirondo, A. \& Stampella, P. (2018). El cultivo del ricino y el amba'y en comunidades guaraníes del nordeste argentino, aproximación etnobotánica de su historia y cosmología. Bonplandia 27: 23-30. https://doi.org/10.30972/bon.2712983

López, J. P., Little, J. R., Ritz, G. F., Rombold, J. S. \& HaHn, W. J. (1987). Árboles comunes del Paraguay. Ñande Yvyra Mata Kuera. Cuerpo de Paz, Colección e Intercambio de Información. Government Printing Office, U.S.

Martínez, G. J. (2010). Las plantas en la medicina tradicional de las sierras de Córdoba. Ed. Del Copista, Córdoba.

Martínez Crovetto, R. (1968). La alimentación entre los indios guaraníes de Misiones (República Argentina). Etnobiológica 4: 1-24. https://doi.org/10.30972/etn.042151

Martínez Crovetto, R. (1978). Una nueva especie de Nicotiana de la flora argentina. Bonplandia 5: 7-10. https://doi.org/10.30972/bon.51-71524

Martínez Crovetto, R. (1980). Identificación botánica del "coro", antiguo fumatorio utilizado por los indios del Chaco (Rep. Argentina). En Editores Mexicanos Unidos (eds.), La Antropología Americanista en la Actualidad. Homenaje a Raphael Girard. Tomo 2, pp. 455-463. México.

Martínez Crovetto, R. (1981). Plantas utilizadas en medicina en el NO de Corrientes. Miscelánea 69: 1-140.

Martínez Crovetto, R. (2012). Estudios etnobotánicos V. Nombres de plantas y su utilidad según los mbya guaraní de Misiones, Argentina. Bonplandia 21: 109133. https://doi.org/10.30972/bon.2121282

Martius, C. F. P. (1843). Systema Materiae Medicae Vegetabilis Brasiliensis. Fleischer, Lipsiae (Leipzig) -Beck in Comm., Vindobonae (Viena). https://doi.org/10.5962/bhl.title.9541

Medeiros, N. H. (2009). Etnobotánica histórica: princípios e procedimentos. Sociedade Brasileira de Etnobiologia e Etnoecologia, Recife.

Montenegro, P. ([1710] 1945). Materia Médica Misionera. Imprenta de la Biblioteca Nacional, Buenos Aires.
Montesano Delchi, A. (1913). Plantas medicinales (extranjeras e indígenas). $1^{\circ}$ Edición. Imprenta Suiza, Buenos Aires.

Morales, R. \& Luque, M. N. (1997). El género Calamintha Mill. (Labiatae) en la Península Ibérica e Islas Baleares. Anales del Jardín Botánico de Madrid 55: 261-276. https://doi.org/10.3989/ajbm.1997.v55.i2.274

Moreno Azorero, R. (1985). Vademécum Médico. Guía terapéutica, medicina tradicional, bioquímica clínica. Ed. Facultad de Ciencias Médicas, Asunción.

Ortega Torres, E., Stutz de Ortega, L. \& Spichiger, R. (1989). Noventa especies forestales del Paraguay. En Spichiger, R. (ed.), Flora del Paraguay. Conservatoire et Jardin botaniques de la Ville de Gèneve, Missouri Botanical Garden.

PARODI, D. (1877). Notas sobre algunas plantas usuales del Paraguay, de Corrientes y de Misiones. Anales de la Sociedad Científica Argentina 4: 80-86; 123-135; 211217; 243-251; 298-315.

PARODI, D. (1886). Notas sobre algunas plantas usuales del Paraguay, de Corrientes y de Misiones. $2^{\circ}$ Edición. Ed. P.E. Coni \& Hijos, Buenos Aires.

PIRONDO, A. 2016. Uso, manejo y acceso al recurso vegetal en comunidades rurales del macrosistema Iberá (Corrientes, Argentina). Tesis doctoral, Universidad Nacional del Nordeste. Corrientes. 196 pp.

Pío Correa, M. P. (1926). Diccionário das plantas úteis do Brasil e das exóticas cultivadas. Vol. 1. Imprenta Nacional, Rio de Janeiro.

PISONIS, G. (1658). De Indiae utriusque re naturali et medica libri quatuordecim, quorum contenta paginas equens exhibet. Amsterdam.

Poletto, R. (2014). Uma trajetória por escrito: Pedro Montenegro S. J. e sua Materia médica misionera. Dissertação para a obtenção de titulo de Mestre, pelo Programa de Pós-Graduação em História da Universidade do Vale do Rio dos Sihnos. São Leopoldo, Brasil. 218 pp.

Ragonese, A. E. \& Martínez Crovetto, R. (1947). Plantas indígenas de la Argentina con frutos o semillas comestibles. Revista de Investigación Agrícola 1: 1-183.

Ratera, E. L. \& Ratera, M. O. (1980). Plantas de la flora argentina empleadas en medicina popular. Ed. Hemisferio Sur, Buenos Aires.

Ricciard, A. \& ChifA, C. (2014). Las plantas medicinales del Nordeste argentino en las crónicas de la época de la Colonia. Ed. Elemento, Buenos Aires.

Ricciardi, A.,Caballero, N. \& Chifa C. (1996). Identificación botánica de las plantas descriptas en "Materia Médica Misionera" usadas en accidentes ofídicos. Rojasiana 3: 239-245. 
Rolón, F. (1910). El Banco Agrícola del Paraguay en la Exposición Internacional de Agricultura de Buenos Aires. Comisión central encargada de la concurrencia del Paraguay a la Exposición Internacional de Agricultura de 1910. Ed. Kraus, Asunción.

Rosso, C. N. (2011). La etnobotánica de los grupos mocovíes de la reducción de San Javier, en el Gran Chaco durante el siglo XVIII. Tesis doctoral, Universidad de Buenos Aires. Buenos Aires. 306 pp.

Rosso, C. N. \& ScARPA, G. F. (2012). Identificaciones botánicas de las plantas empleadas entre los mocovíes en la reducción San Javier durante el siglo XVIII a partir de la obra de Florián Paucke, S. J. En Arenas, P. (ed.), Etnobotánica en zonas áridas y semiáridas del Cono Sur de Sudamérica, pp. 45-70. Sigma, Buenos Aires.

SAGGESE, D. (1959). Yerbas medicinales argentinas. Ed. Antognazzi \& Co., Rosario.

Sainz Ollero, H., Suárez Cardona, F. \& Vázquez de Castro Ontañón, M. (1989). José Sánchez Labrador y los naturalistas jesuitas del Río de la Plata. La aportación de los misioneros jesuitas del siglo XVIII a los estudios medioambientales en el Virreinato del Río de la Plata, a través de la obra de José Sánchez Labrador. Ministerio de Obras Públicas y Urbanismo, Madrid.

SCARPA, G. F. (2000). Estudio etnobotánico de la subsistencia de los criollos del Chaco Noroccidental argentino. Tesis Doctoral, Universidad de Buenos Aires. Buenos Aires. 351 pp. + 12 láms.

ScARPA, G. F. (2004a). Medicinal plants used by the Criollos of Northwestern Argentine Chaco. Journal of Ethnopharmacology 91: 115-135. https://doi.org/10.1016/j.jep.2003.12.003

Scarpa, G. F. (2004b). El síndrome cálido-fresco en la medicina popular criolla del Chaco argentino. Revista de Dialectología y Tradiciones Populares 59: 5-29. https://doi.org/10.3989/rdtp.2004.v59.i2.126

SCARPA, G. F. (2012). Las plantas en la vida de los criollos del oeste formoseño. Medicina, Ganadería, Alimentación y Viviendas Tradicionales. Ed. Rumbo Sur, Buenos Aires.

Scarpa, G. F. \& Anconatani, L. M. (2017). Etnobotánica histórica de las Misiones Franciscanas del este de Formosa II: Identificación y análisis de datos inéditos y reelaboración integral de fuentes ya publicadas a partir de hallazgos documentales. Dominguezia 33: 37-79.

Scarpa, G. F. \& Anconatani, L. M. (2019). La "Materia Médica Misionera" atribuida al jesuita Pedro
Montenegro en 1710: Identificación, sistematización e interpretación de los usos medicinales de las plantas y sus implicancias para la etnobotánica actual. Antiguos Jesuitas en América 7: 27-46. https://doi.org/10.31057/2314.3908.v7.n1.24771

Scarpa, G. F. \& Rosso, C. N. (2018). Etnobotánica histórica de grupos criollos de Argentina III: Identificación taxonómica y análisis de datos no medicinales del Chaco Húmedo en la Encuesta Nacional de Folklore de 1921. Bonplandia 27: 3157. https://doi.org/10.30972/bon.2712984

Scarpa, G. F. \& Rosso, C. N. (2019). Etnobotánica histórica de grupos criollos de Argentina IV: Identificación taxonómica y análisis de datos medicinales del Chaco Húmedo en la Encuesta Nacional de Folklore de 1921. Bonplandia 28: 5-42. https://doi.org/10.30972/bon.2813572

Scarpa, G. F., Rosso, C. N. \& Anconatani, L. M. (2016). Etnobotánica médica de grupos criollos de Argentina: Reconocimiento, análisis y puesta en valor de los datos presentados por el gobierno argentino en la exposición universal de París de 1889. Darwiniana Nueva Serie 4: 291-315. https://doi.org/10.14522/darwiniana.2016.42.714

Schulz, A. G. (1963). Plantas y frutos comestibles de la región chaqueña. Revista Agronómica del Noroeste Argentino 4: 57-83.

Schulz, A. G. (1976). Nombres comunes de las plantas. Talleres Gráficos Moro Hnos., Resistencia.

Sorarú S. B. \& Bandoni, A. L. (1978). Plantas de la medicina popular argentina. Ed. Albatros, Buenos Aires.

Stampella, P. C., Espósito, E. \& Keller, H. A. (2019). Los frutales del Nordeste Argentino en la "Materia Médica Misionera" del Jesuita Pedro Montenegro. Bonplandia 28: 99-116. https://doi.org/10.30972/bon.2823853

Storni, J. S. (1944). Hortus guaranensis. Flora. Universidad Nacional de Tucumán, S. M. de Tucumán.

Toursarkissian, M. (1980). Plantas medicinales de la Argentina: sus nombres botánicos, vulgares, usos y distribución geográfica. Hemisferio Sur, Buenos Aires.

Venegas, J. M. (1788). Compendio de la medicina ó Medicina Práctica. Ed. Felipe de Zúniga y Ontiveros, México.

VIDAL, D. (1782). Tratado patológico teórico-práctico de los tumores humorales: Arreglado para instrucción de los alumnos del Real Colegio de Cirugia de Barcelona. Ed. C. Gibert y Tutó, Barcelona. 
